\title{
Hide and seek in the Bay of Biscaya functional investigation of marine megafauna and small pelagic fish interactions
}

\author{
Lambert Charlotte ${ }^{1,{ }^{*}}$, Authier Matthieu ${ }^{2}$, Doray Mathieu ${ }^{3}$, Doremus Ghislain ${ }^{2}$, Spitz Jerome ${ }^{2}$, \\ Ridoux Vincent ${ }^{1,2}$
}

1 Univ La Rochelle, CNRS, UMR 7372, Ctr Etud Biol Chize, 5 Allees Ocean, F-17000 La Rochelle,
France.
2 Univ La Rochelle, Observ Pelagis, UMS 3462, CNRS, 5 Allees Ocean, F-17000 La Rochelle, France.
${ }^{3}$ IFREMER, EMH, Rue lle Yeu,BP 21105, F-44311 Nantes 03, France.

* Corresponding author : Charlotte Lambert, email address : charlotte.lambert@univ-Ir.fr

\begin{abstract}
:
Prey and predator distributions influence one another. Understanding the scale and the orientation of predator-prey spatial correlations is crucial in foraging ecology. Growing evidence suggests that predator-prey interactions are more constrained by functional characteristics of both the predator and the prey. Unfortunately, in marine pelagic systems, the scale and orientation of spatial correlations between predators and prey have been only little explored from a functional point of view. We tested the existence of fine-scale association between predators and fish functional groups. Visual predator sightings and acoustic fish records were collected synchronously during oceanographic surveys from 2004 to 2014. Prey biomass was integrated by nautical miles and split into four size classes $(<10 \mathrm{~cm}$; $10-20 \mathrm{~cm} ; 20-30 \mathrm{~cm} ;>30 \mathrm{~cm}$ ) and two depth layers (surface, deep). We computed the relative biomass by prey size and depth category from 0 to $12 \mathrm{~nm}$ around predator sightings to determine the predators' proximity to local prey biomass. Two cetaceans (common, bottlenose dolphins) and three seabirds (northern gannets, auks, northern fulmars) were studied. No association was found in fulmars, indicating they probably do not feed on considered fishes in the area. Gannets and auks were positively correlated with local prey biomass for sizes $<20 \mathrm{~cm}$ at both depth layers. Significant negative relationships were found between common dolphins and prey size classes $<20 \mathrm{~cm}$ at both depth layers, and between bottlenose dolphins and all size ranges at the deeper layer. Our results suggest that the fine-scale spatial overlap of predator and prey is influenced by their functional traits, and that prey exhibit predator avoidance behaviour in presence of swimming predators but not of flying ones.
\end{abstract}

Keywords: Bay of Biscay, cetaceans, functional traits, marine top predators, predator avoidance, predator-prey interactions, prey profitability, seabirds 


\section{Introduction}

The identification of strength, scale and orientation of spatial correlations between predators and prey is crucial in foraging ecology. Those spatial correlations are notably shaped by trophic relationships linking the various components of trophic networks. Hence, prey and predator distributions influence one another (MacArthur and Pianka, 1966; Fauchald and Erikstad, 2002). Foraging ecology has traditionally been studied from a taxonomic point of view, typically through the exploration of species-species interactions, but recent and growing evidence suggests that predator-prey interactions are more constrained by functional characteristics of both the predator and the prey (e.g. Zwarts and Wanink, 1993). In marine ecosystems, this functional approach has demonstrated the importance of prey characteristics such as prey depth, body size and energetic contents (Benoit-Bird et al., 2011; Spitz et al., 2014; Hazen et al., 2015). Unfortunately, in marine pelagic systems, the strength, scale and orientation of spatial associations between predators and prey have been only little explored from a functional point of view.

The foraging ecology of predators hinges on the balance between the energy expenditure of the foraging activity and the energy gained from successful foraging events (MacArthur and Pianka, 1966; Pyke, 1984; Stephens and Krebs, 1986). For a predator, the prey detection rate and the probability of capture once prey is detected depends upon the functional characteristics of the prey (Krebs et al., 1977; Scheel, 1993; Zwarts and Wanink, 1993) The selection by a predator of a potential prey (i.e. a species which could be included in its diet) mostly depends on prey availability and prey profitability (e.g. Pyke, 1984; Zwarts and Wanink, 1993; Skov et al., 2000). The availability depends on some prey characteristics such as prey relative abundance, prey depth or prey patch structure (e.g. size, density, inter-patch interval; Benoit-Bird et al., 2013). The availability of prey is however also conditioned by predator capacities to detect and access prey. Predator detection of prey can be visual, acoustic or chemical (Richardson et al., 1995; Silverman et al., 2004; Nevitt, 2008), and prey accessibility is determined by predator foraging strategies such as day or night foraging and surface-, pelagicor benthic-feeding (e.g. Mitani et al., 2004; Benoit-Bird and Au, 2009; Hazen et al., 2015). The profitability of a prey is closely related to energetic costs and benefits. Thus, profitability depends on prey energy content and on predator foraging strategy and anatomy, those two last parameters conditioning predator's handling time (Zwarts and Wanink, 1993; Spitz et al., 2014).

Geographic scale-dependence between species has been demonstrated to positively co-vary with the strength of the negative biotic interaction between predators and prey (Araújo and Rozenfeld, 2014). Such patterns have been confirmed in marine pelagic systems for predator-prey interactions between fish species, where the biotic interaction is strongly positive at large scale, decreases to neutral at medium scale and then becomes negative at a scale smaller than the prey aggregation scale (Rose and Leggett, 1990; Bertrand et al., 2004). These negative associations are possibly due to the effects of predation (prey depletion) and predator avoidance (Rose and Leggett, 1990; Bertrand et al., 2004). However, those negative interactions have only been demonstrated for underwater marine predators.

Although fish-fish predator-prey interactions in pelagic systems are preferentially assessed through simultaneous active acoustic sampling of both parties, simultaneous sampling is often challenging when studying the relationship of other predators with their prey. This is particularly true for cetaceans and seabirds which are often elusive and for which specific techniques are required for distribution monitoring (e.g. passive acoustic or visual surveys). The methodological discrepancies between monitoring fish prey and vertebrate predators make it difficult to significantly test their spatial interactions (Torres et al., 2008). Spatial interactions can hardly be identified from data with imperfect spatio-temporal matching, especially at small-scales (but see Benoit-Bird et al., 2011).

As a result, small-scale predator-prey interactions involving cetaceans and seabirds in pelagic systems remain poorly understood (Fauchald and Erikstad, 2002; Benoit-Bird et al., 2011), especially in a functional ecology context. Cetacean and seabird species present a wide range of contrasting functional characteristics, with regard to foraging strategies, prey detection and feeding techniques as well as energetic requirements. Nevertheless, these species can be split into two general groups based on their primary prey detection techniques: 
predominantly visual for seabirds, and predominantly acoustic for cetaceans (Gaston, 2004; Perrin et al., 2009). Prey species do not have the same ability to detect aerial predators (seabirds) as they do to detect swimming predators (cetaceans). While seabird predators should not be detected until an attack is launched, which allows a very short reaction time, cetacean predators can usually be detected early enough for the prey to engage anti-predation strategies (Wilson and Dill, 2002).

Our study aims to provide new insights into the interactions of prey with two sets of predators with contrasted functional characteristics, cetaceans and prey. Based on the hypothesis that spatial correlation between predators and prey is indicative of trophic relationships between them, we addressed two questions: (i) Do predators significantly correlate with the most profitable prey available in their vicinity? and (ii) Do fine-scale spatial patterns of predator-prey relationships vary according to predators' foraging techniques? We expect to find significant associations only to profitable prey for a given predator, but with potentially different orientation according to predator species. Negative predator-prey associations could be found if prey can detect and avoid their predators (as predicted by Rose and Leggett (1990) and Bertrand et al. (2004)), while positive predator-prey association should be found otherwise.

In order to consider functionally relevant prey fields, we summarized prey along categories according to three main functional criteria which ignored the underlying taxonomy. Firstly, prey species were grouped according to their energy content (profitability to the predator). Secondly, we took into account accessibility to predators in terms of (i) prey body size and (ii) prey depth in the water column. Thirdly, we conservatively assumed that predators are able to detect prey close to them with a high probability, so we characterized prey field from 0 to 12 nautical miles from predators (hereafter local prey field).

The present study helps to elucidate functional trophic interactions between a set of contrasted predator species and small pelagic fishes. We also highlight differences in functional interactions of the two groups of predators with their prey.

\section{Material \& Methods}

\section{$2.1 \quad$ Survey data}

\subsubsection{Survey layout}

This study is based on the data collected through the multidisciplinary oceanographic PELGAS (PELagique GAScogne) surveys, conducted by Ifremer on board $\mathrm{R} / \mathrm{V}$ Thalassa. These annual surveys are ecosystemic cruises conducted to observe the distribution of marine megafauna (visually) and small pelagic fishes (acoustically) in the Bay of Biscay (hereafter BoB), France (Doray et al., 2017). These surveys have been conducted every spring since 2000, along fixed parallel transects from the coast to the shelf break, orthogonal to the main isobaths (Figure 1, Doray et al., 2017). Actual sampling design and total survey effort vary each year depending on logistics and prevailing weather conditions. The analyses for this study were conducted on the area sampled every year between 2004 and 2014. Acoustic data were collected to assess the distribution, biomass and abundance of small pelagic fishes within the water column along the transects; and visual (sighting) data were collected on marine megafauna (e.g. cetaceans, seabirds, large fishes).

\subsubsection{Prey data}

The acoustic surveys were conducted during daytime and continuously using an echosounder along the transects perpendicular to the coast (Doray et al., 2017, see Supplementary File A1 for the realized acoustic sampling). Upon detecting patches of small-pelagic fish with echotraces, acoustic sampling effort was interrupted and trawl hauls were made to groundtruth echotraces with species composition, body size and age structure from the trawled samples. Acoustic and fishing data (Doray et al., 2017) were combined to derive key parameters such as biomass, abundance, mean length and mean weight of target species per sampled nautical mile in two depth layers: from 10 to $30 \mathrm{~m}$ deep (hereafter "surface layer"; depths $<10 \mathrm{~m}$ correspond to an acoustic blind zone), 
and deeper than $30 \mathrm{~m}$ (hereafter "deep layer"). Parameters cannot be estimated by layer for depths smaller than $50 \mathrm{~m}$, therefore in these cases, parameters were estimated for a single layer (from $10 \mathrm{~m}$ deep to the bottom).

Four families of small pelagic fishes were routinely monitored: Clupeidae (anchovy [Engraulis encrasicolus]; sardine [Sardina pilchardus]; sprat [Sprattus sprattus]), Scombridae (Atlantic mackerel [Scomber scrombus]; Atlantic chub mackerel [Scomber colias]), Carangidae (Atlantic horse mackerel [Trachurus trachurus]; Mediterranean horse mackerel [Trachurus mediterraneus]), Gadidae (blue withing [Micromesistius poutassou]). Clupeids, scombrids and carangids were grouped jointly as energy-rich pelagic fishes. Gadids were also monitored, but not considered for this study as they belong to a separate functional group not targeted by predators in the area (Spitz et al., 2012, 2014).

For subsequent analyses, the detected biomass of prey per nautical mile was summarized for each of the four body-size classes $(<10 \mathrm{~cm} ; 10-20 \mathrm{~cm} ; 20-30 \mathrm{~cm} ;>30 \mathrm{~cm}$ ) for each depth layer. Biomass was (log $+1)$-transformed.

\subsubsection{Top predator data}

Standardised top predator observations were collected from 2004 to 2014 following a line transect protocol (Buckland et al., 2001). Effort spanned from sunrise to sunset whenever the vessel speed exceeded 8 knots and stopped during trawling (Supplementary File A2). The main observation platform was the upper deck of the vessel located $16 \mathrm{~m}$ above sea level, but during poor weather conditions (strong winds or rain), observations were conducted from the ship bridge, which is $14 \mathrm{~m}$ above sea level. Observations were conducted by naked eye covering the $180^{\circ}$ area ahead of the bow. Two observers worked simultaneously, each scanning the $90^{\circ}$ on his $/$ her side of the bow. Three trained observers rotated on shifts so that periods of observation were never longer than two consecutive hours. Observation conditions (Beaufort sea-state, swell, glare, cloud cover, platform) were recorded every hour, or whenever observation conditions changed. For each sighting, the species composition, number of individuals, behavior, distance and angle to the observer were recorded. Individuals attending either the research vessel or fishing vessels operating nearby were not recorded.

For subsequent analyses, we only considered predator sightings sampled with Beaufort sea-state $\leq 6$ and with subjective conditions from medium to excellent. Each sighting was matched to the closest sampled acoustic nautical mile. If no acoustic sampling occurred within one nautical mile of a sighting, the sighting was discarded.

Five top predator species were included in this study, three seabirds and two cetaceans, namely: northern fulmars (Fulmarus glacialis), northern gannets (Morus bassanus), auks (mostly common guillemot [Uria aalge] and to a lesser extent razorbill [Alca torda]), common dolphins (Delphinus delphis) and bottlenose dolphins (Tursiops truncatus).

The three seabird species in this study exhibit contrasting foraging strategies along the vertical dimension: northern fulmars are surface feeders and mostly forage by surface seizing despite occasional shallow plunges; northern gannets are plunge divers that can reach depths of $20 \mathrm{~m}$ by plunging alone, and as much as $30 \mathrm{~m}$ when actively pursuing prey underwater; auks are surface divers, chasing prey by active swimming from 10 to $60 \mathrm{~m}$ deep, with occasional dives down to $180 \mathrm{~m}$ deep (Gaston, 2004; del Hoyo et al., 2010). The three seabird groups are daytime foragers.

The two cetacean species can forage within the whole water column and adjust their strategies depending on the target prey (Perrin et al., 2009). However, in the BoB, the bottlenose dolphin feeds in the demersal zone more than the common dolphin (Spitz et al., 2006). Bottlenose dolphins also feed on larger prey than the common dolphin (Spitz et al., 2006). These two dolphins species forage mostly from dusk to dawn (Bräger, 1993; Hanson and Defran, 1993; Goold, 2000). Social interactions are their main activity during daytime, with occasional foraging events (Pusineri et al., 2007). Since the timing of observation do not match those of dolphin foraging activity, the relationships identified here do not relate to direct trophic interactions. However, these relationships are likely to provide insight into behaviour exhibited by prey as a reaction to the presence of predators.

Not only do these predators differ in feeding techniques, but also in the way they locate prey aggregations. 
Northern fulmars use visual and olfactory cues (Nevitt and Bonadonna, 2005; Nevitt, 2008), while northern gannets are mostly visual predators; both are attracted to feeding sites by indirect evidence of the presence of their prey through public information such as other birds actively feeding or fishing vessels (Silverman et al., 2004). Auks are mostly visual underwater predators. Finally, dolphins locate their prey both by passive acoustics and echolocation (Richardson et al., 1995; Gannon et al., 2005) as well as chemoreception, although little is known on this in delphinids (Bouchard et al., 2017).

All studied predators rely at least partially on energy-rich small pelagic fishes. We thus expected all these predators to spatially correlate to the categories of prey they prey upon. That is, we made the assumption that a spatial correlation between a predator and a prey category would be indicative of a trophic relationship between them.

\subsection{Data processing}

\subsubsection{Local prey field estimation}

We computed the residual biomass of the associated acoustically sampled prey for each predator sighting at increasing distances around it. The minimum, 0, corresponds to the sampled nautical mile around the sighting, and the maximum of 12 nautical miles around it is the distance between two adjacent transects (Figure 2). For each distance $i$, from 0 to 12 , the residual biomass $\varepsilon_{x}$ was computed as $\forall i_{0} \leftrightarrow 12 ; \varepsilon_{x_{i}}=\bar{x}_{i}-\overline{x_{12}}$. Therefore, by construction, residual prey biomass converged to zero for the maximum distances. When a sighting occurred close to a transect edge in the acoustic sampling, the maximum distance was restricted to the distance from the sighting to this end. This distance-based residual biomass was computed for the four prey body-size classes and the two depth layers for all predator sightings collected from 2004 to 2014, and constrained to the nautical miles sampled on the same day as the predator sighting being considered in order to ensure temporal consistency.

The summary statistics by distance were then computed for each year for the five studied predator species, providing annual mean relationships between the residual biomass and the distance for each prey size and layer depth, weighted by the number of predator sightings per year. The average predator-prey relationship over the ten years was then estimated using local polynomial regression with package ggplot2 (Wickham, 2009) in $\mathrm{R}$ 3.2.3 (R Core Team, 2015).

We expected three kinds of predator-prey relationships (Figure 2 inset). If predators were positively associated with prey biomass, then the highest prey biomass was expected to occur in close proximity to predator sightings. As a result, the relationship would show a positive mode for small distances (curve a, Figure 2 inset). Conversely, a negative association between predators and prey would result in the highest prey biomass occurring far from predator sightings, and the relationship would show a negative mode for small distances (curve b, Figure 2 inset). Finally, a flat pattern is expected in the case of no functional predator-prey association, or in the case of a uniform prey field (curve c, Figure 2 inset).

\subsubsection{Simulated predator data and local prey field}

In order to assess whether observed relationships were functional and not artefactual, we simulated random sighting distributions of each predator. A hundred datasets were simulated by generating randomly distributed sightings, with an annual number of sightings equal to that observed to ensure similar sampling variability.

Local prey fields were estimated for each simulated (pseudo)predator sighting dataset as above (see previous section, "Local prey field estimation"). This procedure enabled us to estimate a "null envelope" around the expected relationship for randomly distributed predators with respect to prey. Whenever the observed predatorprey relationship was not inside this null envelope, the observed relationship was deemed significant. 


\section{Results}

\subsection{Distributions of predators and prey within the Bay of Biscay}

\subsubsection{Prey}

Small pelagic fishes of less than $10 \mathrm{~cm}$ were mostly detected along the coast from the Loire estuary to the southern BoB, both in the surface and deep layers, but in 2011 they were detected over the whole BoB (Supplementary File A1). The distributions of detections of the second size class $(10-20 \mathrm{~cm})$ was similar to the first size class in the surface layer, while detections were more widespread in the deeper layer, with numerous detections up to the shelf edge (Supplementary File A2). The third prey size class $(20-30 \mathrm{~cm})$ was detected along the coast as well as at the outer shelf in the surface layer, but over the whole BoB in the deep layer (except in 2010 and 2012 when there were fewer detections; Supplementary File A3). Finally, detections of individuals larger than $30 \mathrm{~cm}$ were very scarce within the surface layer, and occurred mostly over the outer shelf in the deeper layer (Supplementary File A4).

\subsubsection{Predators}

Northern fulmar distributions showed little variation over the years. This species was mostly distributed over the outer shelf, with a varying southward extension of its range depending on the year (Figure 3 and Supplementary File C1). The northern gannet was the most abundant species and was widespread over the whole BoB irrespective of the year (Figure 3 and Supplementary File C2). Auks were also abundant, but were distributed mostly inshore, with their offshore extension varying across years (maximum in 2008 and 2013; Figure 3 and Supplementary File C3). Common dolphin sightings were mostly distributed over the inner shelf of the BoB (Figure 3 and Supplementary File C4). Finally, the sightings of bottlenose dolphins were concentrated along the shelf edge (Figure 3 and Supplementary File C5).

\subsection{Relationships between predators and small pelagic fishes}

Fulmars were the only of the five studied predator species that did not exhibit any significant relationship to biomass of small pelagic fish. The observed relationship remained within the null envelope regardless of the prey size and layer depth (Figure 4a). In addition, these relationships were generally flat (curve $c$, Figure 2 inset).

Gannets and auks exhibited a clearly non-random positive association with the two first size classes of prey $(<10$ and 10-20 cm) in both surface and deep layers (curve $a$, Figure 2 inset). The local biomass of small pelagic fishes were highest at closer distances from predator sightings for both gannets and auks (Figure 4b-c), but the correlation was stronger for the 10-20 cm size class than for the $<10 \mathrm{~cm}$ size class for gannets (this correlation was only marginally different from the null envelope), while the correlation was similar between the two size classes for auks (Figure 4b).

Cetaceans also exhibited non-random associations with different categories of prey, but these associations were negative in all cases (curve $b$, Figure 2, inset). The local biomass of the two first prey size classes $(<10$ and 10-20 cm) was lower at shorter distances for common dolphin in both surface and deep layers (Figure 5a). However, the relationship between common dolphin and prey were only marginally non-random in the deep layer for prey $<10 \mathrm{~cm}$ and in the surface layer for prey of $10-20 \mathrm{~cm}$.

For bottlenose dolphins, the local prey biomass was lowest at shorter distances for the four size classes in the deep layer (Figure 5b), although the relationship was only marginally different from random for the 20-30 $\mathrm{cm}$ and $>30 \mathrm{~cm}$ size classes. 


\section{Discussion}

\subsection{Strengths and weaknesses}

Based on the simultaneous monitoring of prey and predators during multiannual ecosystemic surveys, we found clear small-scale predator-prey relationships conditioned by functional characteristics of both parties. This was made possible by the use of a new method of using predator sightings as focal points and examining how prey acoustic detections varied with increasing distance from that focal point.

This approach provided several technical advantages. First, the method eliminated the disparity in the prey and predator data types (acoustic $v s$ visual detection respectively) by using only prey data to characterize prey fields around focal points. Second, the ecosystemic surveys permitted us to examine a larger segment of predator populations compared to that of more traditional techniques used to explore predator-prey relationships. For cetaceans, our results are expected to be more representative of the whole population than studies relying on stomach contents, which are based on stranded individuals (e.g. Spitz et al., 2006; Meynier et al., 2008). For seabirds, our results have the great advantage of incorporating the whole non-breeding segment of the population (juveniles, immatures and failed breeders) which is excluded by studies using stomach content analyses, which are necessarily based on colonies (e.g. Lewis et al., 2003; Hamer et al., 2007).

The main limitation of visual surveys for predator monitoring is that the sampling is not exhaustive since diving individuals are not detected. This issue is crucial for cetaceans, as they are only detectable when surfacing. However, the method used here overcame this issue by considering only known presence of predators, but not their absence. Indeed, availability bias is an important issue when the aim is inferring population-wide parameters from surveys (Pollock et al., 2006), i.e. when deriving true absence is necessary; which was not the case here.

\subsection{Functional predator-prey relationships}

The first goal of this study was to determine whether predators associate preferentially with profitable prey available around them. To do this, we explored the spatial association of predator sightings with local prey biomass, subdivided into four prey size categories and two depth layers.

In northern Europe, the northern fulmars is known to have a quite generalist diet, relying on a wide panel of prey, from pelagic fishes to crustaceans and to fisheries discards and offals (Phillips et al., 1999; Danielsen et al., 2010). The absence of spatial correlation with the small pelagic fishes highlighted during this study suggests that northern fulmars do not rely on these prey for their subsistence in the Bay of Biscay, a region where the diet of the species remained quite poorly known. It is plausible that northern fulmars rely on fisheries discards or on living prey with lower trophic levels instead of the small pelagic fishes considered here.

Contrary to fulmars, auks and gannets were strongly associated with higher local biomass of forage fish with body size between 0 and $20 \mathrm{~cm}$, both in the surface and deep layers. Both auks and gannets are known to rely on fish smaller than $20 \mathrm{~cm}$ (Lewis et al., 2003; Hamer et al., 2007; Benoit-Bird et al., 2011; Thaxter et al., 2013), with auks relying more than gannets on smaller sized fish (Certain et al., 2011). With the present study, we showed those species had similar preference in the Bay of Biscay (gannets had a strongest association to the 10-20 cm size class than to the $<10 \mathrm{~cm}$ class, while auks exhibited associations of equal strength with both classes). Auks and gannets are both able to reach and exceed depths of $30 \mathrm{~m}$ while diving, thus explaining their association with the deeper layer (del Hoyo et al., 2010). Based on these results, these two groups seem to partially share a similar functional trophic niche in the Bay of Biscay.

Our results seem a valuable complement to those obtained from previous studies, mostly based on breeding gannets (Lewis et al., 2003; Hamer et al., 2007). During PELGAS surveys, gannets are assumed to be nonor failed- reproductive individuals since the closest colony is too far away from the BoB, in western English Channel, for breeding gannets to forage in the study area. Based on individuals attending colonies, the 10-20 cm prey size range has been shown to be preserved over gannet's lifetime (Hamer et al., 2007) unlike other foraging characteristics, including the extent of foraging trips and their duration. Hamer et al. (2007) demonstrated that 
chick-rearing gannets were flexible regarding many components of their foraging strategies (prey species, trip durations etc.), but not regarding their target prey size, which was between 7 and $32 \mathrm{~cm}$. The results presented here therefore complement this knowledge, by showing that prey size range is also preserved for individuals released from reproductive duties.

Common dolphins are cooperative feeders which are known to select prey items based on a set of functional traits (Spitz et al., 2014). To compensate for their energetically expensive foraging strategies and lifestyle, they rely extensively on small schooling energy-rich pelagic fishes smaller than $20 \mathrm{~cm}$ (Pusineri et al., 2007; Spitz et al., 2014, 2018). Bottlenose dolphin are the only predator species studied here which forages mainly on large fish (Spitz et al., 2006; Louis et al., 2014), mostly in deeper layers.

Our results therefore are in line with a functional segregation between the two dolphin species (MéndezFernandez et al., 2013): common dolphins are more related to smaller prey over the whole water column while bottlenose dolphins are related to the whole spectrum of prey size but exclusively in the deeper layer.

\subsection{Predator-specific orientation of predator-prey relationship}

Associations between predators and prey were identified for distances ranging from 0 to about 6-8 nautical miles around predator sightings, but diminished for distances larger than 8 nautical miles. This distance matched the prey patch scale previously identified within the BoB (Petitgas, 2003). Predator-prey associations should theoretically be negative at such a scale in pelagic systems (Rose and Leggett, 1990; Bertrand et al., 2004; Araújo and Rozenfeld, 2014), however the orientations of these associations were different for cetaceans and seabirds.

Cetacean sightings were significantly negatively correlated with their preferential prey. This negative relationship might be the result of prey dispersion away from dolphins, possibly originating in either stand alone or mixed effect of active depletion by foraging dolphins or prey anti-predator behavioural adjustments (Rose and Leggett, 1990; Bertrand et al., 2004). Prey may be able to avoid dolphins by detecting them either visually, acoustically or chemically, hence creating a kind of "halo" around detected dolphins. In the BoB, dolphins are mostly involved in social interactions during the day, which is when survey is conducted, and forage mostly at dawn, dusk or at night (Pusineri et al., 2007). For this reason, the depletion of small pelagic fish by dolphins actively foraging possibly partly explains the negative relationships seen here, but we suggest this phenomenon is of lower importance than predator avoidance behaviour by prey.

Some small pelagic fishes, especially clupeids, are known to have a wide range of ultrasonic hearing capabilities allowing them to detect echolocation clicks from dolphins, and probably to identify various species of predators based on their click signatures (Wilson and Dill, 2002). Several experiments have demonstrated predator-avoidance behaviour in response to exposure to echolocation clicks from dolphins, such as an increase in swimming speed and a downward movement of schools (Wilson and Dill, 2002; Doksæter et al., 2009; Mann et al., 1998). In addition, fish perform more pronounced predator avoidance behaviour if they have been previously exposed to echolocation sounds (Rieucau et al., 2016). During the day, dolphins are mostly involved in travel and social interactions and use acoustic communication extensively (Bräger, 1993; Hanson and Defran, 1993; Neumann, 2001), which makes them easily detectable by their potential prey. Although current knowledge of chemical detection of cetaceans by pelagic fish is very limited, many fish species have been shown to recognize chemical signatures of fish predators (Brown, 2003; Mitchell et al., 2015). Such a process could also contribute to the predator-avoidance mechanism suggested by our results.

The avoidance of predators implies that small pelagic fishes can detect the presence of dolphins, either acoustically or chemically. In this study, the evidence of behavioural avoidance by only the prey categories known to be preyed upon by the two dolphin species is in line with this hypothesis. However, this avoidance should not be of great trouble for dolphins. They should be able to thwart this avoidance when feeding from dusk to dawn (Bräger, 1993; Hanson and Defran, 1993; Goold, 2000). Dolphins can modulate their echolocation strategies according to the target prey, i.e. using more passive listening (Barrett-Lennard et al., 1996; Gannon et al., 2005) or reducing the source level in case of sound sensitive prey while using louder echolocation clicks 
in case of poorly hearing prey (Simon et al., 2007).

For seabirds, however, significant associations with functionally preferential prey were strongly positive. This pattern suggests that the theory based on pelagic organisms (fishes or cetaceans) may not hold for flying predators. Seabird avoidance behaviour by prey might occur at a smaller scale than that expected for cetaceans and predatory fishes (at the school or individual fish scale), since seabirds cannot be detected before the foraging event is triggered (Fauchald and Erikstad, 2002; Fauchald, 2009). As a consequence, our results suggest that the combination of functional traits of both predators and prey directly impacts the spatial scaling of predatorprey interactions, with interactions occurring at smaller scale for flying predators than swimming ones. This hypothesis would benefit from further refinement with a broader set of species. Exploration of larger and smaller scale predator-prey associations for seabirds would help to determine whether negative associations do indeed occur at the school or individual prey levels, as hypothesized.

\section{Conclusion}

The prey accessibility for a predator depends on two factors. First, prey size: is the predator able to catch prey efficiently? Second, their distribution within the water column: are the prey accessible considering the predator's diving capacities? For these reasons, we split the prey dataset into four size and two depth categories. In addition, we only considered prey species profitable for the studied predators by considering only small pelagic fishes characterized by high energetic contents. Our results confirmed the value of considering clusters of prey species sharing similar functional characteristics for predators (Spitz et al., 2014). This can only be achieved by collecting and analysing detailed quantitative (size, energetic content) and spatially explicit (horizontal and vertical distribution) information on prey.

The accessibility of prey in terms of functional traits -depth and size- was crucial in determining the association of seabirds and cetaceans with prey biomass. Northern fulmars were shown to have no association with small pelagic fishes in our study area, while gannets and auks were positively related to small pelagic fishes from 0 to $20 \mathrm{~cm}$ in body length. Regarding cetaceans, common dolphins were negatively related to small pelagic fishes from 0 to $10 \mathrm{~cm}$ long, while bottlenose dolphins were negatively related to the four prey size classes within the deeper layer only.

Our functional approach has allowed us to highlight a differential pattern in predator-prey associations depending on functional characteristics of both predators and prey. We demonstrated that prey engage smallscale anti-predator adjustments when facing cetaceans, but not when facing seabirds.

The advantage of the present analysis, compared to previous methods described in the literature, is that we have a snapshot of the populations at large, including the non-breeding segment of seabird populations rarely sampled through traditional methods, which are restricted to colonies.

\section{Funding}

CL's PhD was funded by the French ministry in charge of research (Ministère de l'Enseignement Supérieur et de la Recherche, MESR). The MEGASCOPE program is supported by the French Agency for Biodiversity (Agence Française pour la Biodiversité, AFB) and the French Ministry for an Ecological and Solidary Transition (Ministère de de La Transition Écologique et Solidaire). PELGAS surveys are supported and conducted by Ifremer.

\section{Acknowledgements}

We are indebted to Ifremer and the crew members on board the $R / V$ Thalassa and to all the observers who participated in the surveys. We are deeply grateful to Carin Reisinger for her help on the manuscript writing. 


\section{Authors' contributions}

- GD, MD, MA, CL, JS collected the data

- CL, MA, JS, VR designed methodology

- CL performed analyses

- CL led the writing of the manuscript

\section{References}

Araújo, M. B., Rozenfeld, A., 2014. The geographic scaling of biotic interactions. Ecography 37 (5), $406-415$. 1,7

Barrett-Lennard, L. G., Ford, J. K., Heise, K. A., 1996. The mixed blessing of echolocation: differences in sonar use by fish-eating and mammal-eating killer whales. Animal Behaviour 51 (3), 553-565. 7

Benoit-Bird, K. J., Au, W. W., 2009. Cooperative prey herding by the pelagic dolphin, Stenella longirostris. The Journal of the Acoustical Society of America 125 (1), 125-137. 1

Benoit-Bird, K. J., Battaile, B. C., Heppell, S. A., Hoover, B., Irons, D., Jones, N., Kuletz, K. J., Nordstrom, C. A., Paredes, R., Suryan, R. M., otherss, 2013. Prey patch patterns predict habitat use by top marine predators with diverse foraging strategies. PLoS One 8 (1), e53348. 1

Benoit-Bird, K. J., Kuletz, K., Heppell, S., Jones, N., Hoover, B., 2011. Active acoustic examination of the diving behavior of murres foraging on patchy prey. Marine Ecology Progress Series. 1, 6

Bertrand, A., Barbieri, M. A., Córdova, J., Hernández, C., Gómez, F., Leiva, F., 2004. Diel vertical behaviour, predator-prey relationships, and occupation of space by jack mackerel (Trachurus murphyi) off Chile. ICES Journal of Marine Science 61 (7), 1105-1112. 1, 2, 7

Bouchard, B., Lisney, T. J., Campagna, S., Célérier, A., 2017. Do bottlenose dolphins display behavioural response to fish taste? Applied Animal Behaviour Science. 4

Bräger, S., 1993. Diurnal and seasonal behavior patterns of bottlenose dolphins (Tursiops truncatus). Marine Mammal Science 9 (4), 434-438. 3, 7

Brown, G. E., 2003. Learning about danger: chemical alarm cues and local risk assessment in prey fishes. Fish and Fisheries 4 (3), 227-234. 7

Buckland, S. T., Anderson, D. R., Burnham, K. P., Laake, J. L., Borchers, D. L., Thomas, L., Jul. 2001. Introduction to Distance Sampling: Estimating Abundance of Biological Populations, Édition: new ed Edition. OUP Oxford, Oxford ; New York. 3

Certain, G., Masse, J., Van Canneyt, O., Petitgas, P., Dorémus, G., Santos, M. B., V., R., January 2011. Investigating the coupling between small pelagic fish and marine top predators using data collected from ecosystem-based surveys. Marine Ecology Progress Series 422, 23-39. 6

Danielsen, J., Van Franeker, J., Olsen, B., Bengtson, S., 2010. Preponderance of mesopelagic fish in the diet of the northern fulmar (fulmarus glacialis) around the faroe islands. Seabird 23, 66-75. 6

del Hoyo, J., Elliot, A., Christie, D., 2010. Handbook of the Birds of the World. Lynx Edicions. 3, 6

Doksæter, L., Rune Godø, O., Olav Handegard, N., Kvadsheim, P. H., Lam, F.-P. A., Donovan, C., Miller, P. J., 2009. Behavioral responses of herring (Clupea harengus) to 1-2 and 6-7 kHz sonar signals and killer whale feeding sounds. The Journal of the Acoustical Society of America 125 (1), 554-564. 7 
Doray, M., Petitgas, P., Romagnan, J. B., Huret, M., Duhamel, E., Dupuy, C., Spitz, J., Authier, M., Sanchez, F., Berger, L., et al., 2017. The PELGAS survey: Ship-based integrated monitoring of the Bay of Biscay pelagic ecosystem. Progress in Oceanography. 2

Fauchald, P., 2009. Spatial interaction between seabirds and prey: review and synthesis. Marine Ecology Progress Series 391, 139-151. 8

Fauchald, P., Erikstad, K. E., 2002. Scale-dependent predator-prey interactions: the aggregative response of seabirds to prey under variable prey abundance and patchiness. Marine Ecology Progress Series 231, $279-291$. 1,8

Gannon, D. P., Barros, N. B., Nowacek, D. P., Read, A. J., Waples, D. M., Wells, R. S., 2005. Prey detection by bottlenose dolphins, Tursiops truncatus: an experimental test of the passive listening hypothesis. Animal Behaviour 69 (3), 709-720. 4, 7

Gaston, A. J., 2004. Seabirds: a natural history. Yale University Press. 2, 3

Goold, J. C., 2000. A diel pattern in vocal activity of short-beaked common dolphins, Delphinus delphis. Marine Mammal Science 16 (1), 240-244. 3, 7

Hamer, K., Humphreys, E., Garthe, S., Hennicke, J., Peters, G., Grémillet, D., Phillips, R., Harris, M., Wanless, S., 2007. Annual variation in diets, feeding locations and foraging behaviour of gannets in the north sea: flexibility, consistency and constraint. Marine Ecology Progress Series 338 (2), 5-305. 6

Hanson, M. T., Defran, R., 1993. The behavior and feeding ecology of the pacific coast bottlenose dolphin, tursiops truncatus. Aquatic Mammals 19, 127-127. 3, 7

Hazen, E. L., Friedlaender, A. S., Goldbogen, J. A., 2015. Blue whales (Balaenoptera musculus) optimize foraging efficiency by balancing oxygen use and energy gain as a function of prey density. Science Advances 1 (9), e1500469. 1

Krebs, J. R., Erichsen, J. T., Webber, M. I., Charnov, E. L., 1977. Optimal prey selection in the great tit (parus major). Animal Behaviour 25, 30-38. 1

Lewis, S., Sherratt, T. N., Hamer, K. C., Harris, M. P., Wanless, S., 2003. Contrasting diet quality of northern gannets morus bassanus at two colonies. Ardea 91 (2), 167-176. 6

Louis, M., Fontaine, M. C., Spitz, J., Schlund, E., Dabin, W., Deaville, R., Caurant, F., Cherel, Y., Guinet, C., Simon-Bouhet, B., 2014. Ecological opportunities and specializations shaped genetic divergence in a highly mobile marine top predator. Proceedings of the Royal Society B 281 (1795), 20141558. 7

MacArthur, R. H., Pianka, E. R., 1966. On optimal use of a patchy environment. American Naturalist, $603-609$. 1

Mann, D. A., Lu, Z., Hastings, M. C., Popper, A. N., 1998. Detection of ultrasonic tones and simulated dolphin echolocation clicks by a teleost fish, the American shad (Alosa sapidissima). The Journal of the Acoustical Society of America 104 (1), 562-568. 7

Méndez-Fernandez, P., Pierce, G. J., Bustamante, P., Chouvelon, T., Ferreira, M., González, A. F., López, A., Read, F. L., Santos, M. B., Spitz, J., et al., 2013. Ecological niche segregation among five toothed whale species off the nw iberian peninsula using ecological tracers as multi-approach. Marine biology 160 (11), 2825-2840. 7

Meynier, L., Pusineri, C., Spitz, J., Santos, M. B., Pierce, G. J., Ridoux, V., 2008. Intraspecific dietary variation in the short-beaked common dolphin Delphinus delphis in the Bay of Biscay: importance of fat fish. Marine Ecology Progress Series 354, 277. 6 
Mitani, Y., Watanabe, Y., Sato, K., Cameron, M. F., Naito, Y., 2004. 3d diving behavior of weddell seals with respect to prey accessibility and abundance. Marine Ecology Progress Series 281, 275-281. 1

Mitchell, M. D., Chivers, D. P., McCormick, M. I., Ferrari, M. C., 2015. Learning to distinguish between predators and non-predators: understanding the critical role of diet cues and predator odours in generalisation. Scientific reports 5.7

Neumann, D. R., 2001. Activity budget of free-ranging common dolphins (Delphinus delphis) in the northwestern Bay of Plenty, New Zealand. Aquatic Mammals 27 (2), 121-136. 7

Nevitt, G. A., 2008. Sensory ecology on the high seas: the odor world of the procellariiform seabirds. Journal of Experimental Biology 211 (11), 1706-1713. 1, 4

Nevitt, G. A., Bonadonna, F., 2005. Sensitivity to dimethyl sulphide suggests a mechanism for olfactory navigation by seabirds. Biology Letters 1 (3), 303-305. 4

Perrin, W. F., Wursig, B., et al., 2009. Encyclopedia of marine mammals. Academic Press. 2, 3

Petitgas, P., 2003. A method for the identification and characterization of clusters of schools along the transect lines of fisheries-acoustic surveys. ICES journal of Marine Science 60 (4), 872-884. 7

Phillips, R., Petersen, M., Lilliendahl, K., Solmundsson, J., Hamer, K., Camphuysen, C., Zonfrillo, B., 1999. Diet of the northern fulmar Fulmarus glacialis: reliance on commercial fisheries? Marine Biology 135 (1), 159-170. 6

Pollock, K. H., Marsh, H. D., Lawler, I. R., Alldredge, M. W., 2006. Estimating animal abundance in heterogeneous environments: an application to aerial surveys for dugongs. Journal of wildlife management 70 (1), 255-262. 6

Pusineri, C., Magnin, V., Meynier, L., Spitz, J., Hassani, S., Ridoux, V., Jan. 2007. Food and Feeding Ecology of the Common Dolphin (Delphinus delphis) in the Oceanic Northeast Atlantic and Comparison with Its Diet in Neritic Areas. Marine Mammal Science 23 (1), 30-47. 3, 7

Pyke, G. H., 1984. Optimal foraging theory: a critical review. Annual Review of Ecology and Systematics 15, 523-575. 1

R Core Team, 2015. R: A Language and Environment for Statistical Computing. R Foundation for Statistical Computing, Vienna, Austria, ISBN 3-900051-07-0.

URL http://www.R-project.org/ 4

Richardson, W., Greene, J., Malme, C., Thompson, D., 1995. Marine mammals and noise. Academic Press, San Diego, CA. 1, 4

Rieucau, G., Sivle, L. D., Olav Handegard, N., 2016. Herring perform stronger collective evasive reactions when previously exposed to killer whales calls. Behavioral Ecology 27 (2), 538-544. 7

Rose, G. A., Leggett, W. C., 1990. The importance of scale to predator-prey spatial correlations: an example of atlantic fishes. Ecology 71 (1), 33-43. 1, 2, 7

Scheel, D., 1993. Profitability, encounter rates, and prey choice of african lions. Behavioral ecology 4 (1), 90-97. 1

Silverman, E. D., Veit, R. R., Nevitt, G. A., 2004. Nearest neighbors as foraging cues: information transfer in a patchy environment. Marine Ecology Progress Series 277, 25-36. 1, 4

Simon, M., Wahlberg, M., Miller, L. A., 2007. Echolocation clicks from killer whales (Orcinus orca) feeding on herring (Clupea harengus). The Journal of the Acoustical Society of America 121 (2), 749-752. 8 
Skov, H., Durinck, J., Andell, P., 2000. Associations between wintering avian predators and schooling fish in the Skagerrak-Kattegat suggest reliance on predictable aggregations of herring Clupea harengus. Journal of Avian Biology 31 (2), 135-143. 1

Spitz, J., Ridoux, V., Brind'Amour, A., 2014. Let's go beyond taxonomy in diet description: testing a trait-based approach to prey-predator relationships. Journal of Animal Ecology 83 (5), 1137-1148. 1, 3, 7, 8

Spitz, J., Ridoux, V., Trites, A., Laran, S., Authier, M., 2018. Prey consumption by cetaceans reveals the importance of energy-rich food webs in the Bay of Biscay. Progress in Oceanography. 7

Spitz, J., Rousseau, Y., Ridoux, V., 2006. Diet overlap between harbour porpoise and bottlenose dolphin: An argument in favour of interference competition for food? Estuarine, Coastal and shelf science 70 (1), 259-270. $3,6,7$

Spitz, J., Trites, A. W., Becquet, V., Brind'Amour, A., Cherel, Y., Galois, R., Ridoux, V., 2012. Cost of living dictates what whales, dolphins and porpoises eat: the importance of prey quality on predator foraging strategies. PLoS One 7 (11), e50096. 3

Stephens, D., Krebs, J., 1986. Foraging theory. Monographs in Behavior and Ecology. Princeton University Press, Princeton. 1

Thaxter, C. B., Daunt, F., Grémillet, D., Harris, M. P., Benvenuti, S., Watanuki, Y., Hamer, K. C., Wanless, S., 2013. Modelling the effects of prey size and distribution on prey capture rates of two sympatric marine predators. PloS one 8 (11), e79915. 6

Torres, L. G., Read, A. J., Halpin, P., 2008. Fine-scale habitat modeling of a top marine predator: do prey data improve predictive capacity. Ecological Applications 18 (7), 1702-1717. 1

Wickham, H., 2009. ggplot2: Elegant Graphics for Data Analysis. Springer-Verlag New York. 4

Wilson, B., Dill, L. M., 2002. Pacific herring respond to simulated odontocete echolocation sounds. Canadian Journal of Fisheries and Aquatic Sciences 59 (3), 542-553. 2, 7

Zwarts, L., Wanink, J. H., 1993. How the food supply harvestable by waders in the wadden sea depends on the variation in energy density, body weight, biomass, burying depth and behaviour of tidal-flat invertebrates. Netherlands Journal of Sea Research 31 (4), 441-476. 1 


\section{Figures}

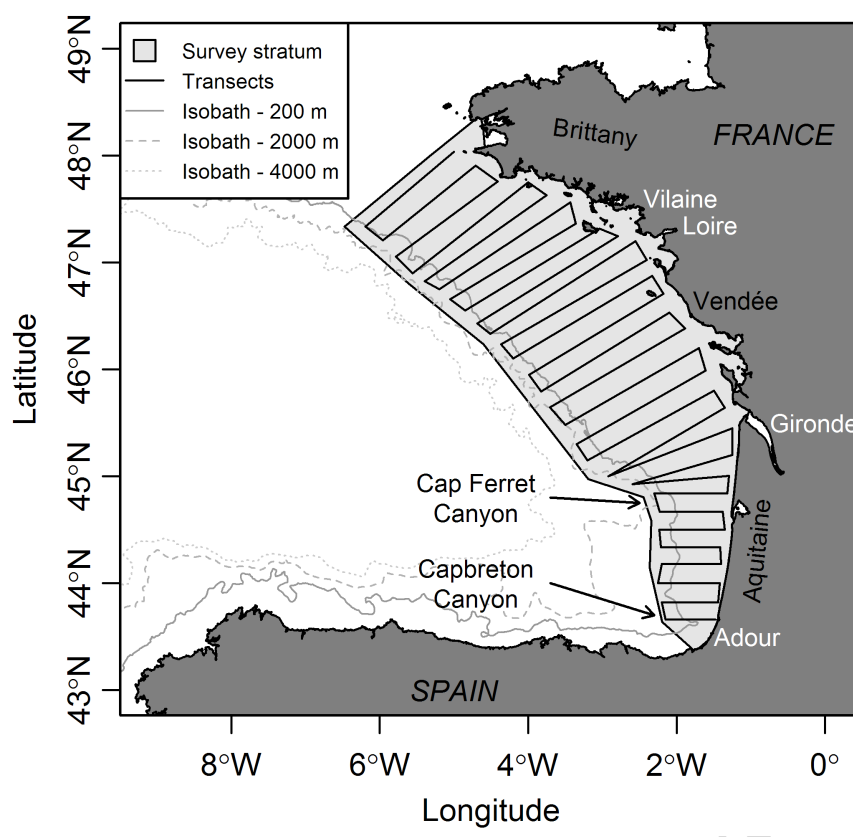

Figure 1. Survey area and theoretical sampling design of PELGAS survey. The isobaths are indicated in grey, the four main estuaries in white, the geographical localities in black.

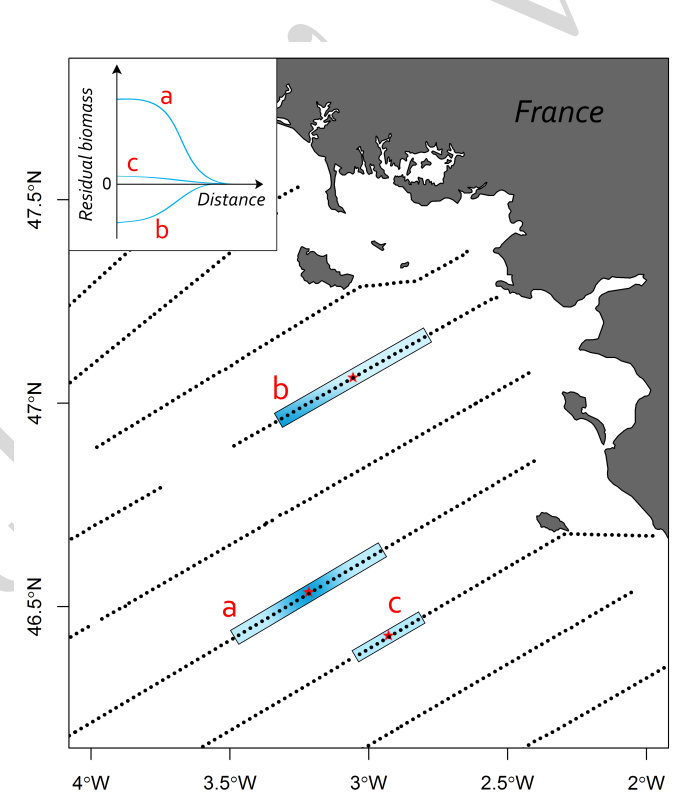

Figure 2. Summary of the method used to compute the residual biomass around predator sightings and the expected result. The black dots represent the acoustically sampled nautical miles, small red stars the predator sightings. The blue rectangles represent the maximum distance computed around a sighting: the maximum distance was 12 nautical miles around a sighting ( $\mathrm{a}$ and $\mathrm{b}$ ), but when arriving at the edge of a transect, the distance was limited to the number of miles to the edge (e.g. five nautical miles in the case c). The blue gradient within rectangles represents the prey biomass distribution. The inset indicates expected relationships between residual biomass and distance from predator in these three cases: a, sighting preferentially associated to biomass; b, sighting avoiding biomass; c, no pattern. 


\section{A - Seabirds}
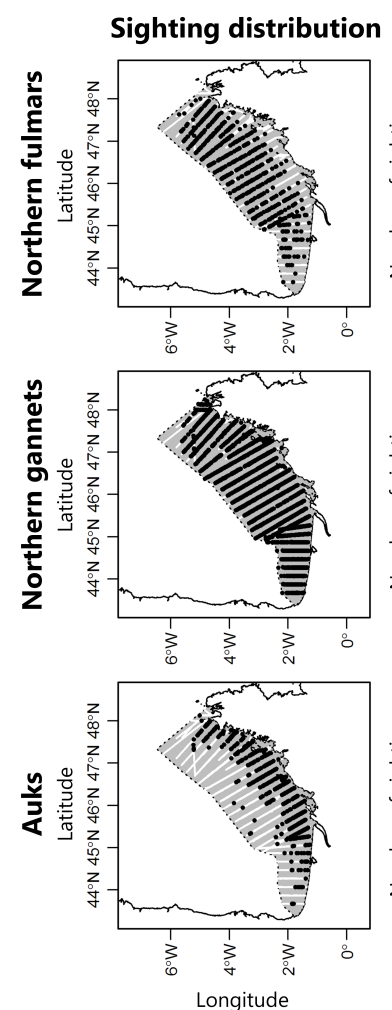

Sighting number
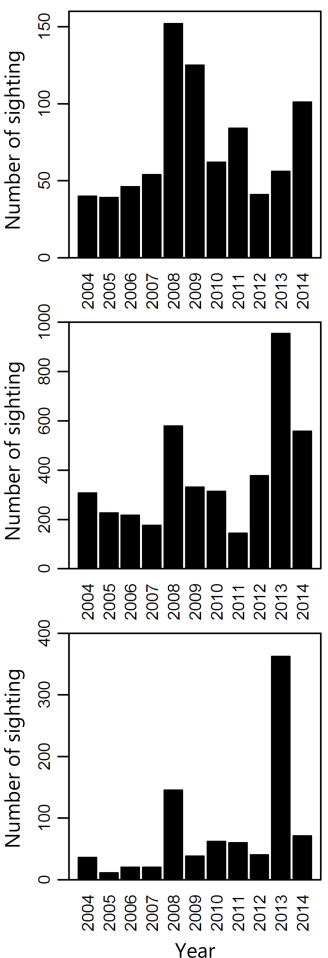

B - Cetaceans
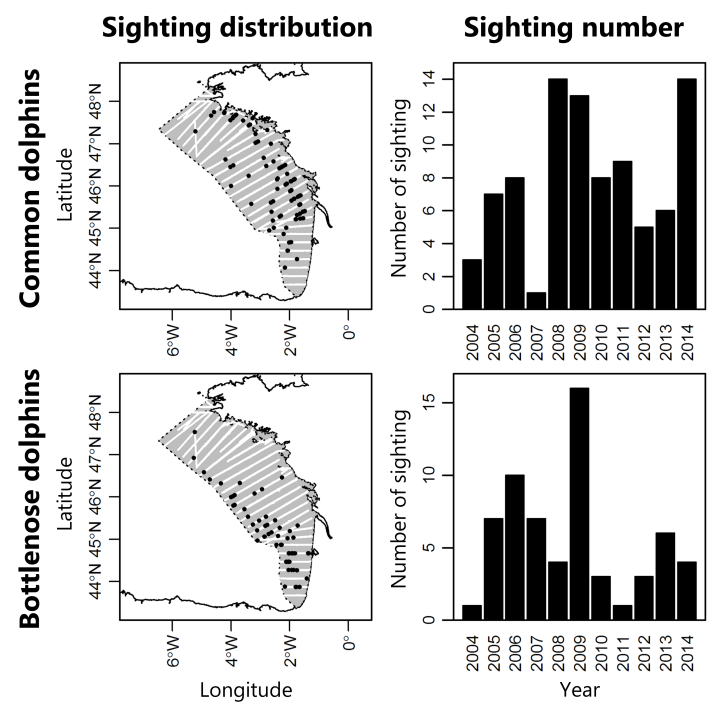

Figure 3. Distribution and number of predator sightings within the Bay of Biscay during PELGAS surveys from 2004 to 2014 for (A) seabirds and (B) cetaceans. Black dots represent predator sightings, white lines represent sampled transects and the grey polygon the PELGAS stratum. 

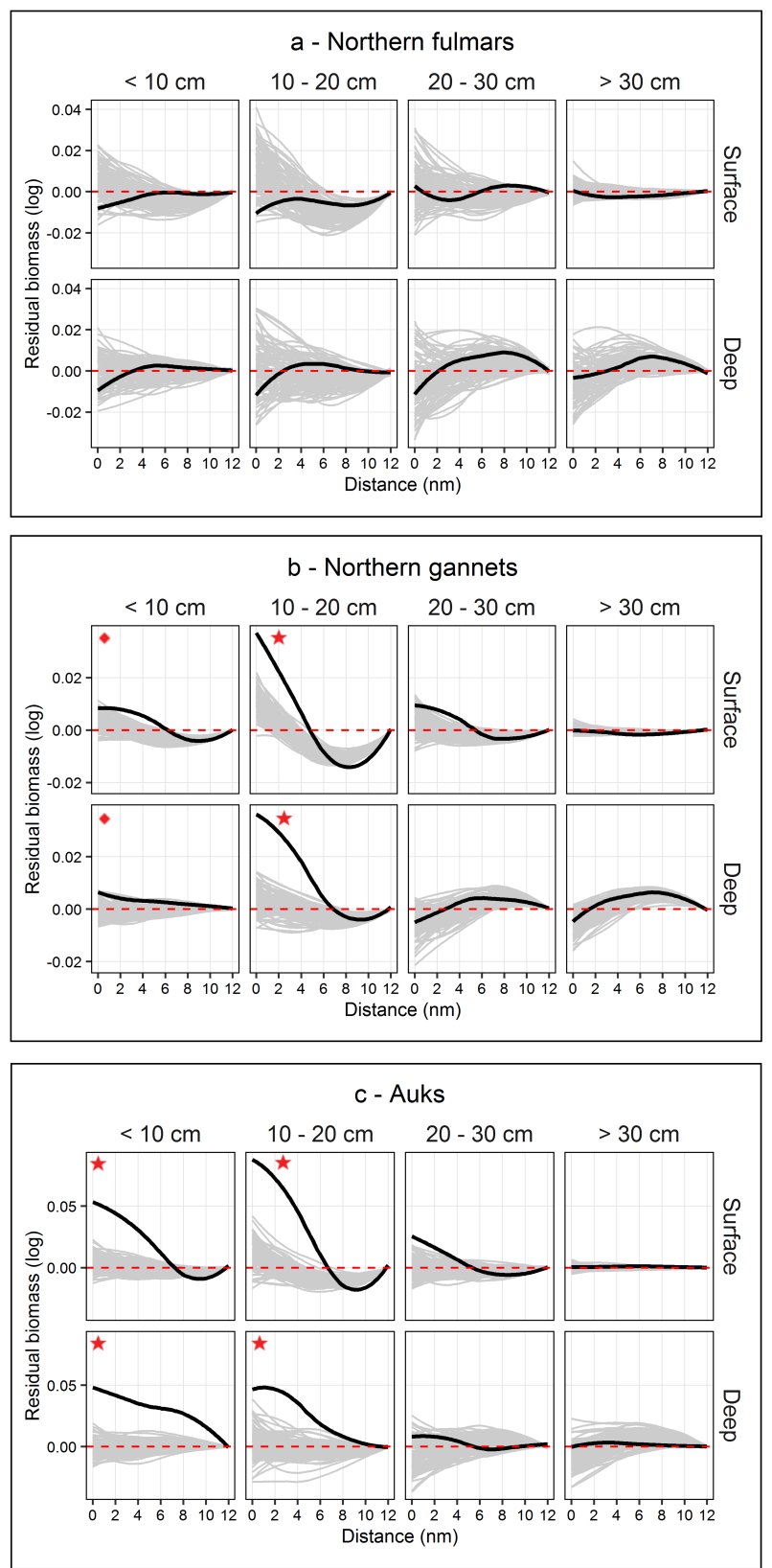

Figure 4. Average relationships (in black) between the residual biomass (log) and the distance from the sighting (in nautical miles) for the three seabird groups, the four size classes (columns) and two depth layers (rows). The stars indicate relationships clearly diverging from random distributions (in grey), the diamonds indicate marginal relationships compared to the random distributions. 

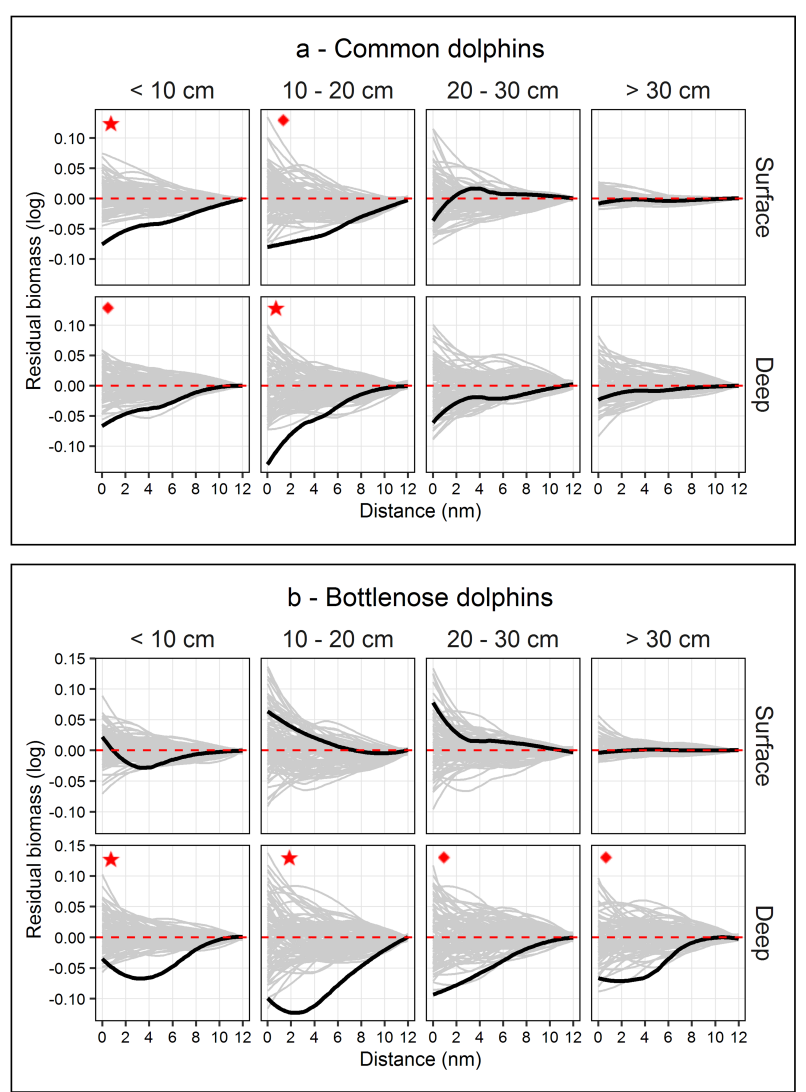

Figure 5. Average relationships (in black) between the residual biomass (log) and the distance from the sighting (in nautical miles) for the two cetacean species, the four size classes (columns) and two depth layers (rows). The stars indicate relationships clearly diverging from random distributions (in grey), the diamonds indicate marginal relationships compared to the random distributions. 


\section{Supplementary file A}

\section{Distribution of realised transect efforts}

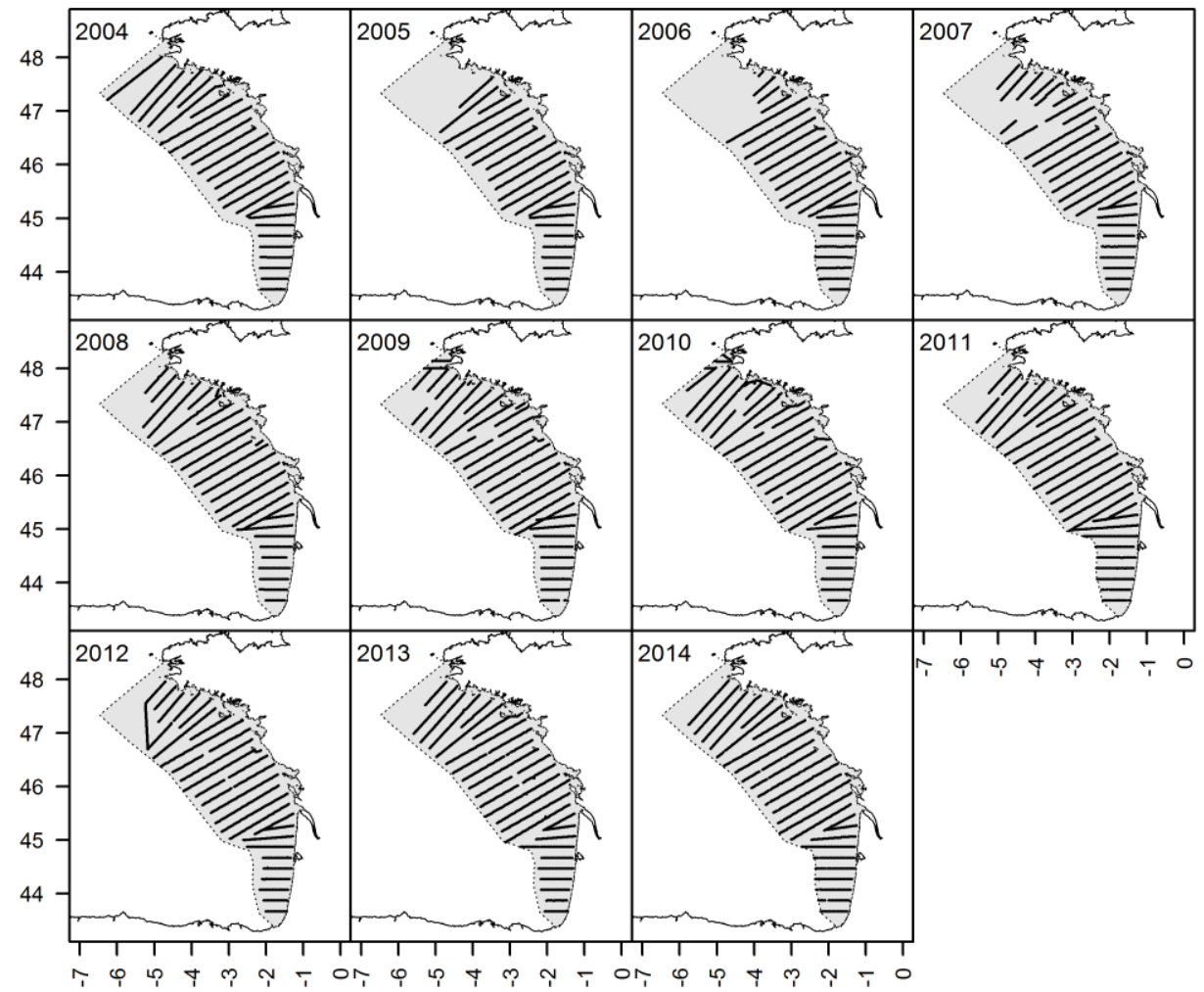

Figure A1 - Realised PELGAS acoustic sampling transects from 2004 to 2014.

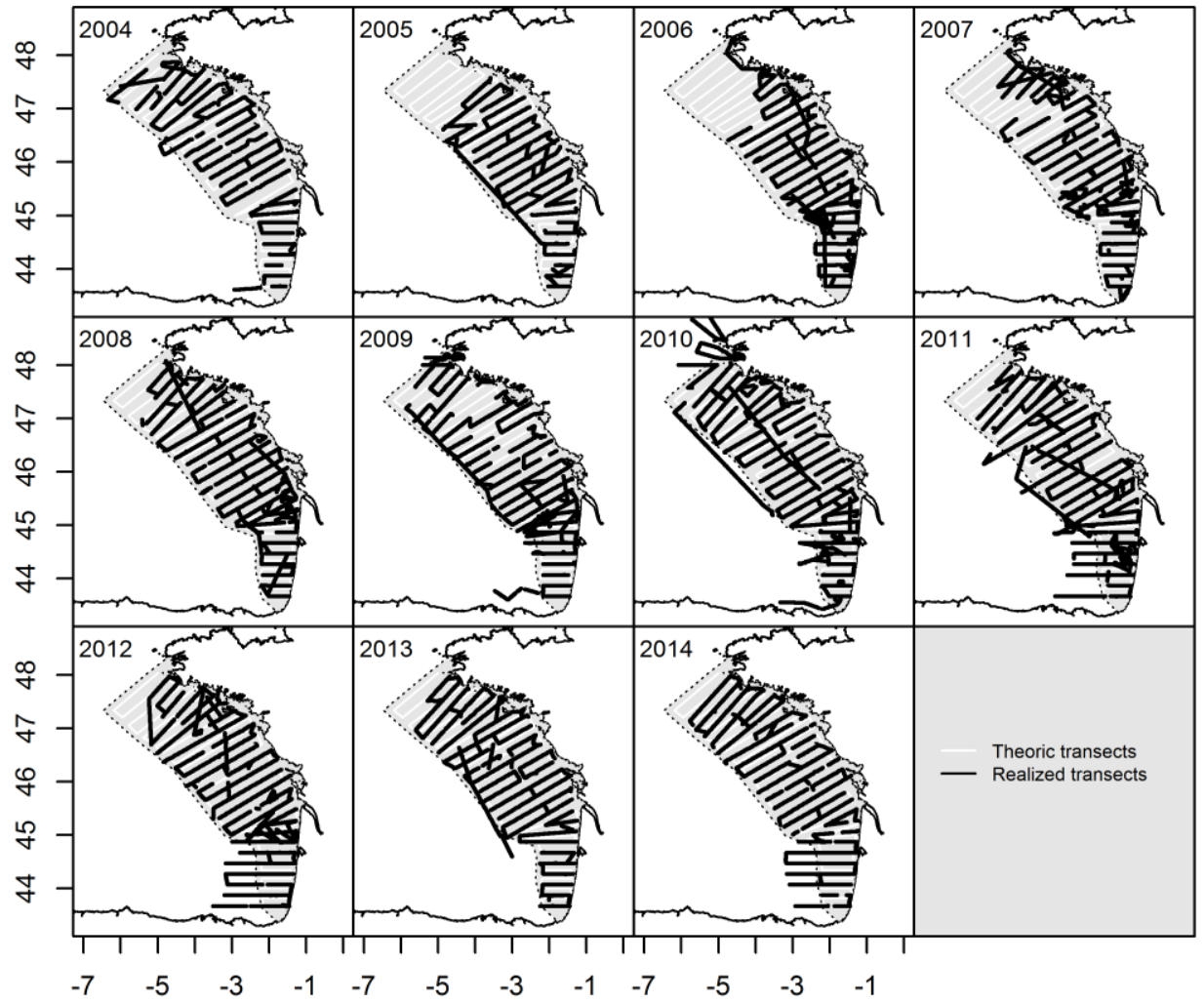

Figure A2 - Realised PELGAS route with megafauna sighting efforts from 2004 to 2014, including inter-transect routes. Total distance covered per year: 2004: $3723.3 \mathrm{~km}$; 2005: $3714.6 \mathrm{~km}$; 2006: $4914.2 \mathrm{~km}$; 2007: 4429.5 km; 2008: 5108.6 km; 2009: 5942.3 km; 2010: 6799.5 km; 2011: 6067.5 km; 2012: 5511.3 km; 2013: 4502.6 $\mathrm{km} ; 2014: 4406.4 \mathrm{~km}$ 


\section{Supplementary file B}

\section{Distributions of small pelagic fish acoustic detections}
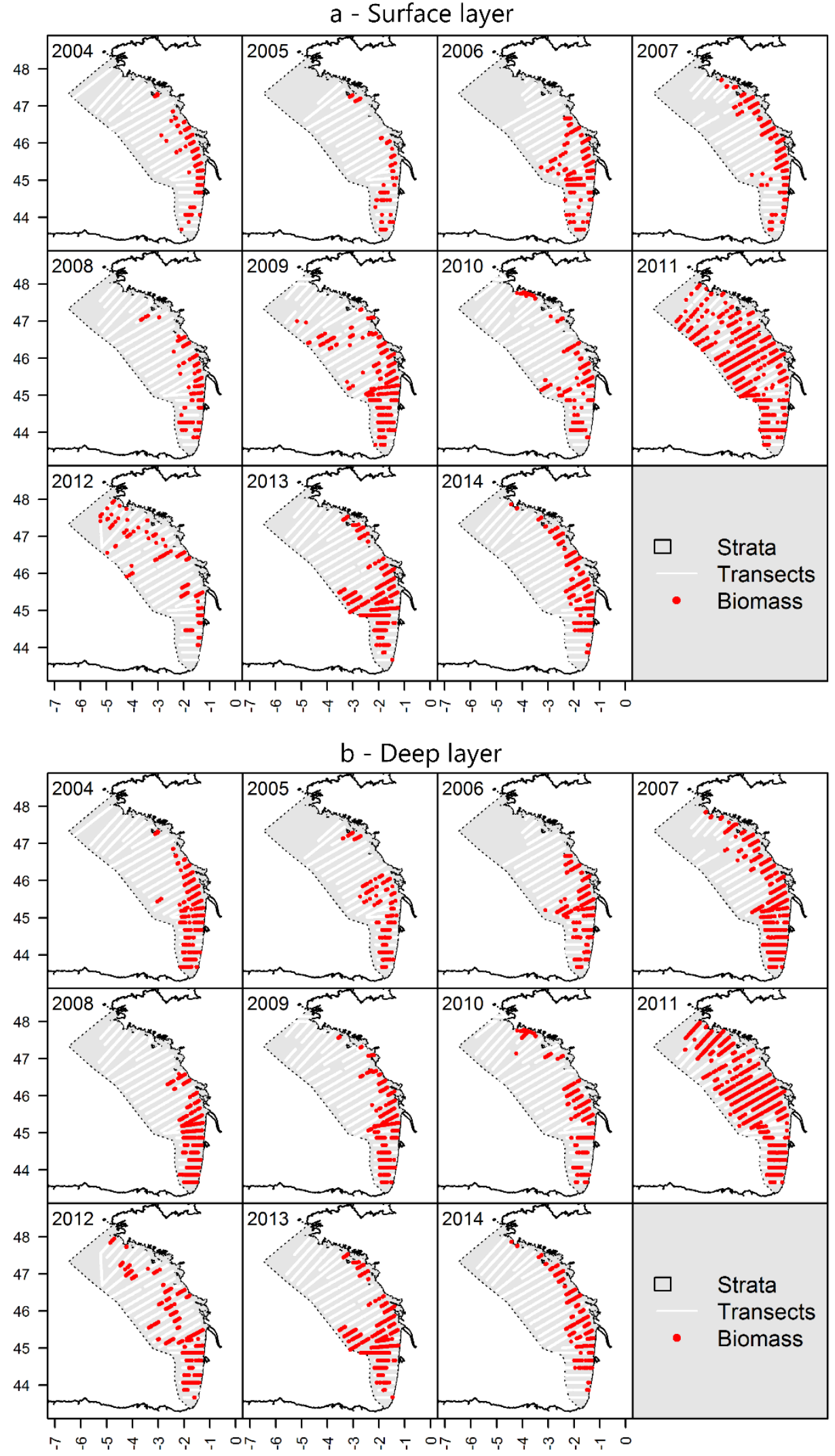

Figure B1 - Distributions of acoustic detections of small pelagic fishes smaller than $10 \mathrm{~cm}$ in the surface layer (a) and deep layer (b). 
a - Surface layer
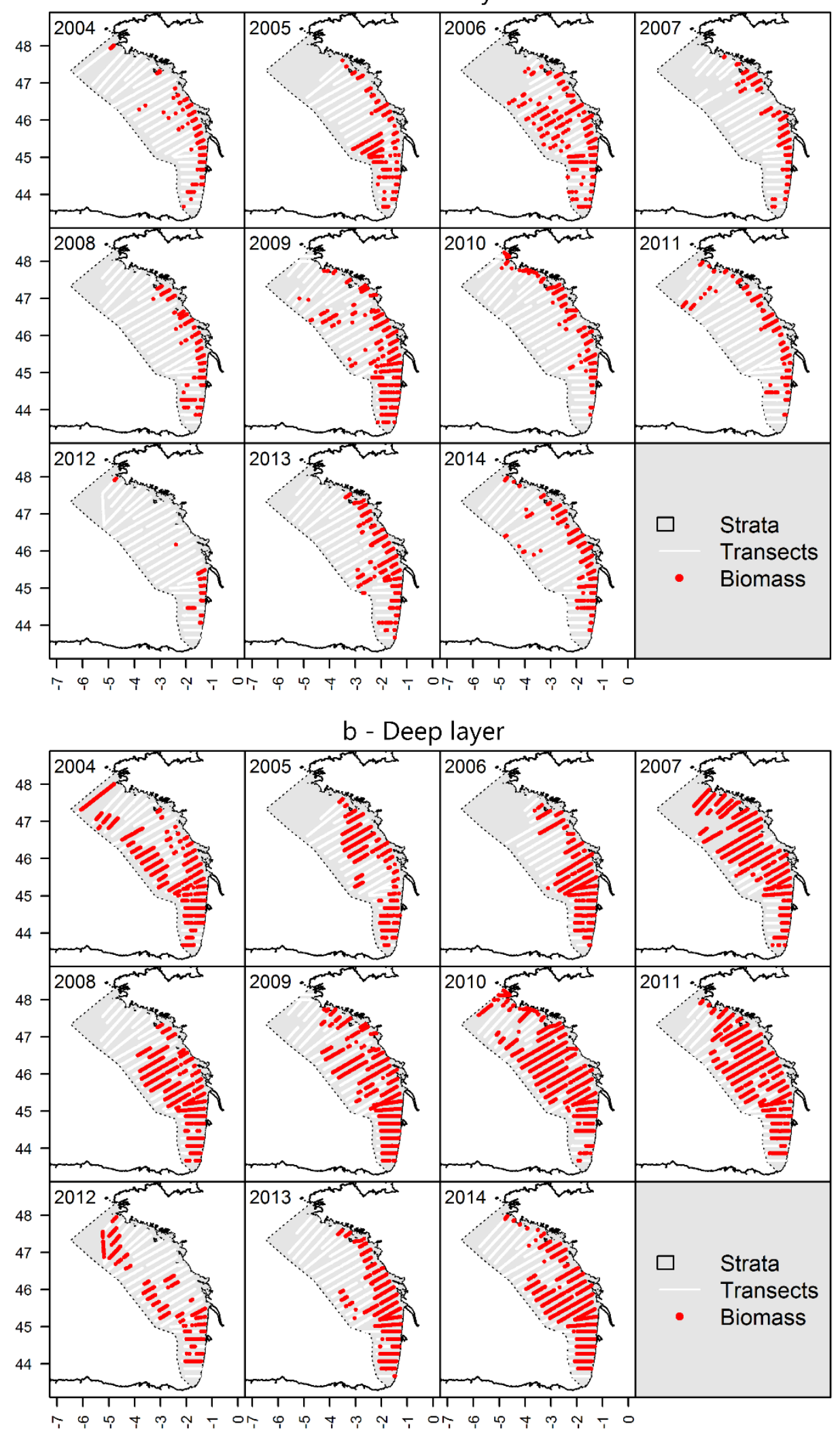

Figure B2 - Distributions of acoustic detections of small pelagic fishes between 10 and $20 \mathrm{~cm}$ long in the surface layer (a) and deep layer (b). 
a - Surface layer

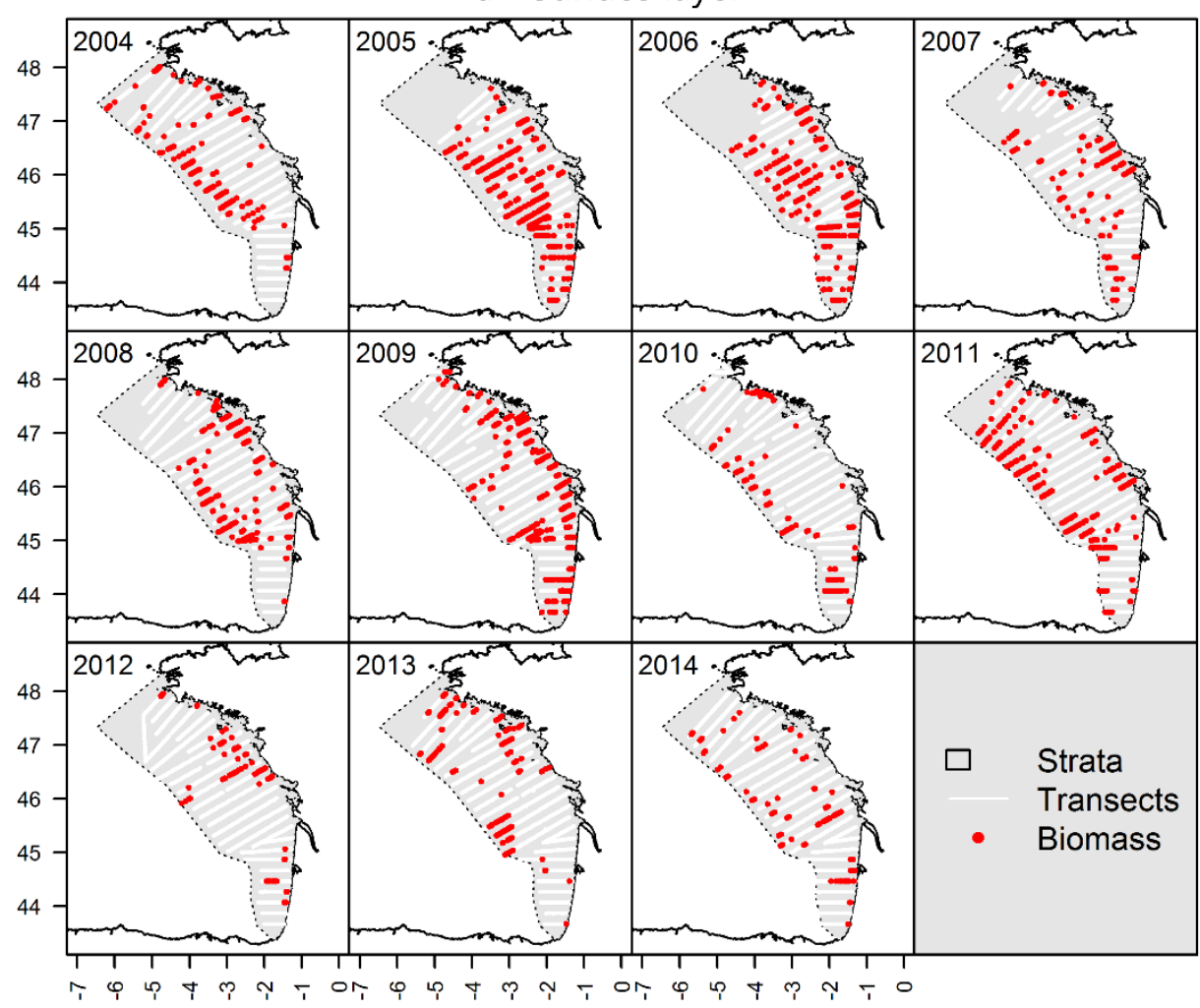

b - Deep layer

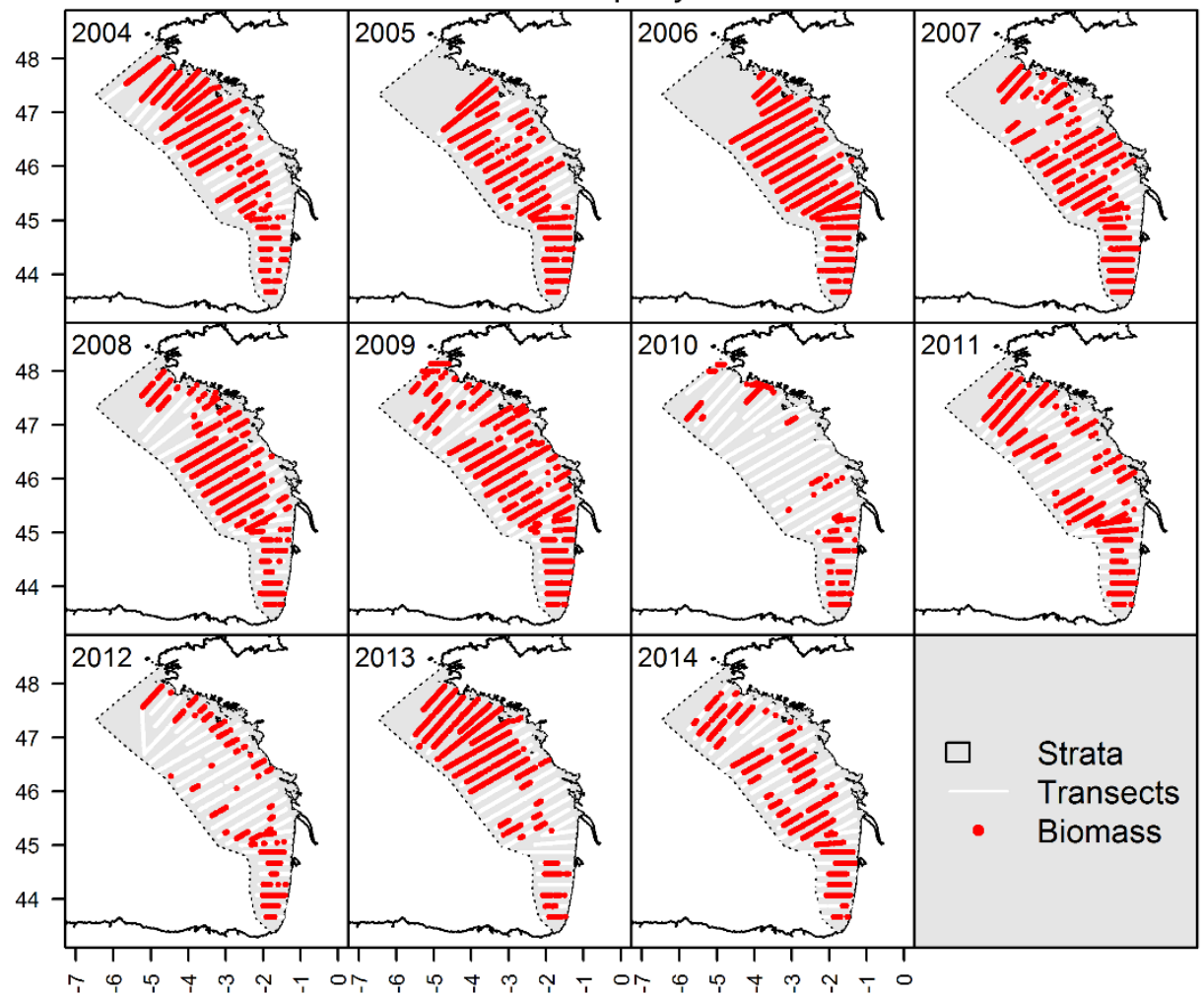

Figure B3 - Distributions of acoustic detections of small pelagic fishes between 20 and $30 \mathrm{~cm}$ long in the surface layer (a) and deep layer (b). 

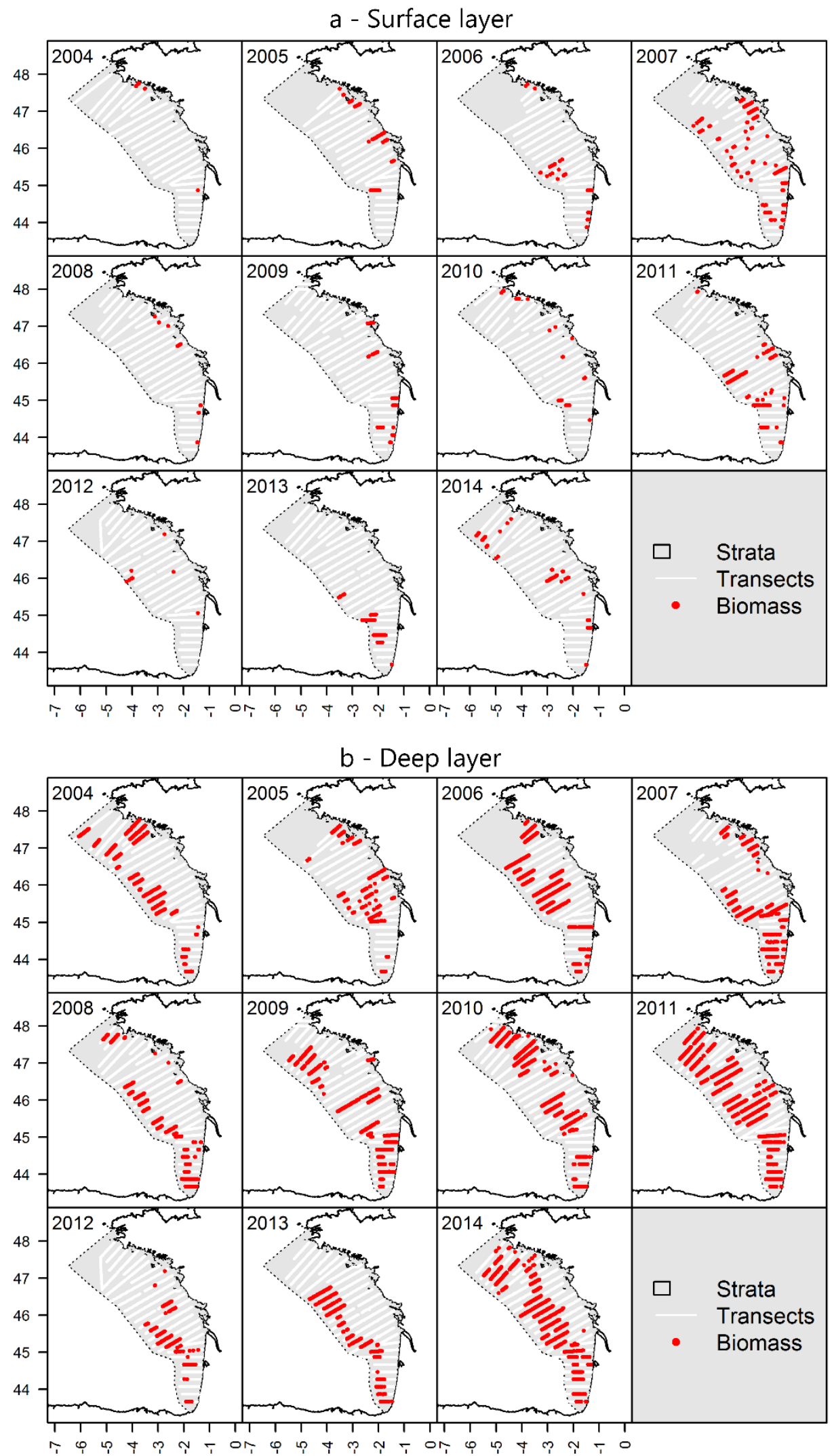

Figure B4 - Distributions of acoustic detections of small pelagic fishes larger than $30 \mathrm{~cm}$ in the surface layer (a) and deep layer (b). 


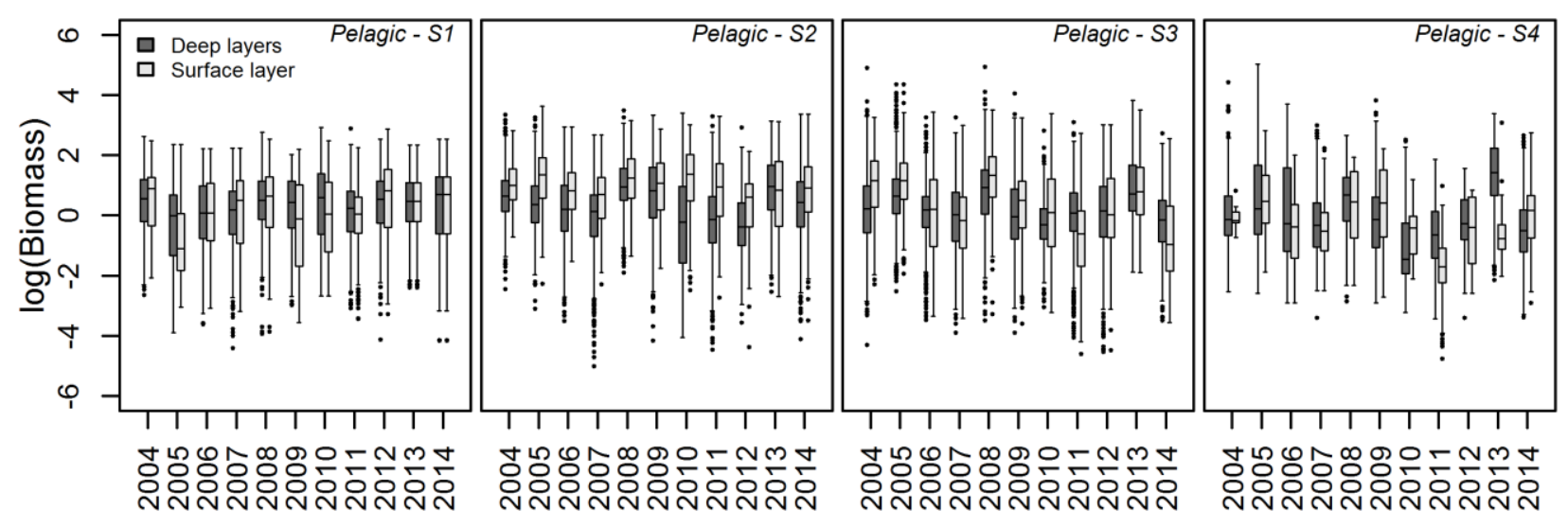

Figure B5 - Biomass (log) of the four size classes of small pelagic fishes ( $\mathrm{S} 1:<10 \mathrm{~cm}$; S2: 10-20 $\mathrm{cm}$; S3: 20-30 cm; S4: $>30 \mathrm{~cm}$ ) detected within the Bay of Biscay between 2004 and 2014 for the surface and deep layers. 


\section{Supplementary file C}

\section{Distributions of top predator sightings}

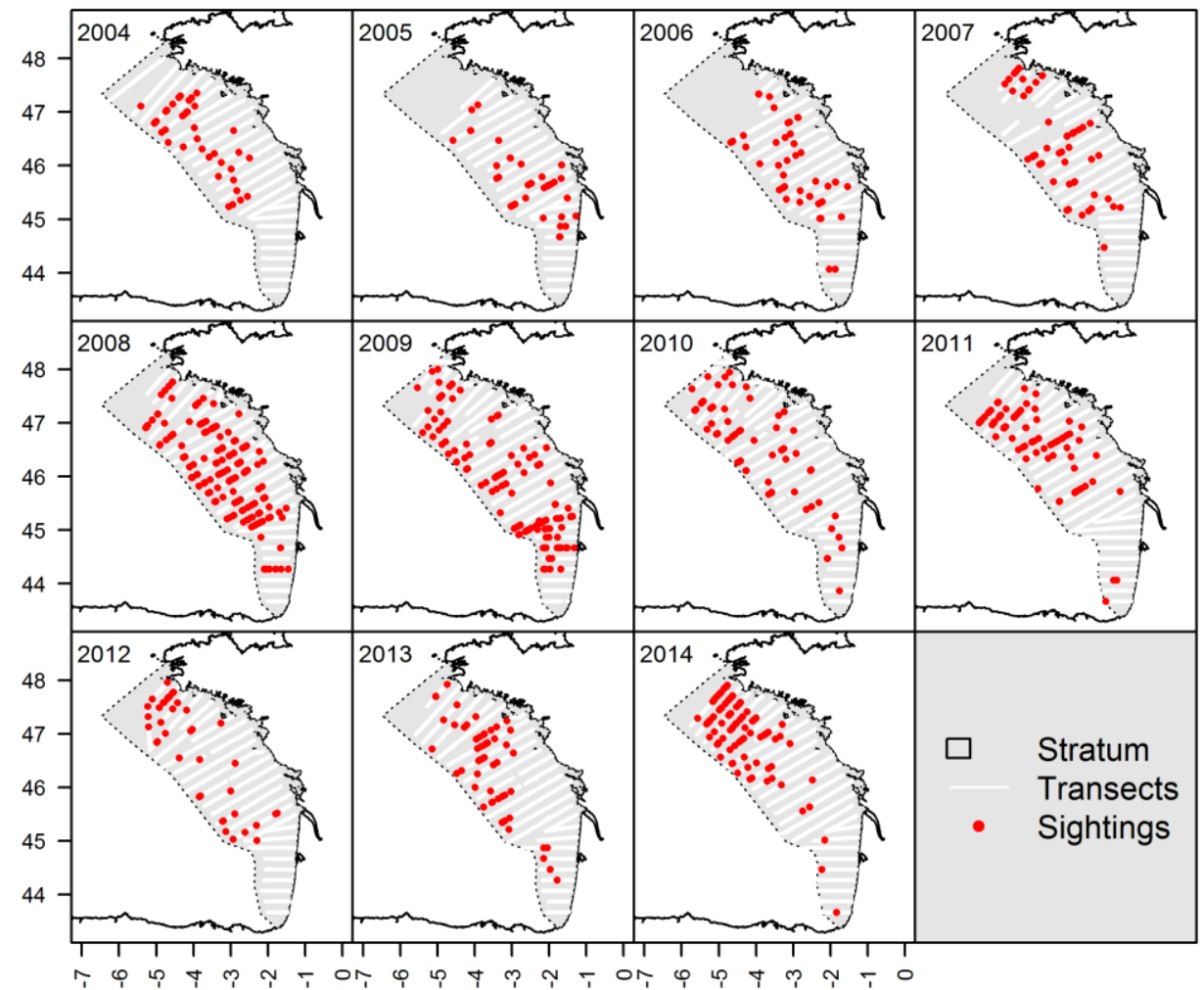

Figure C1 - Distributions of northern fulmar sightings associated to acoustic detections from 2004 to 2014.

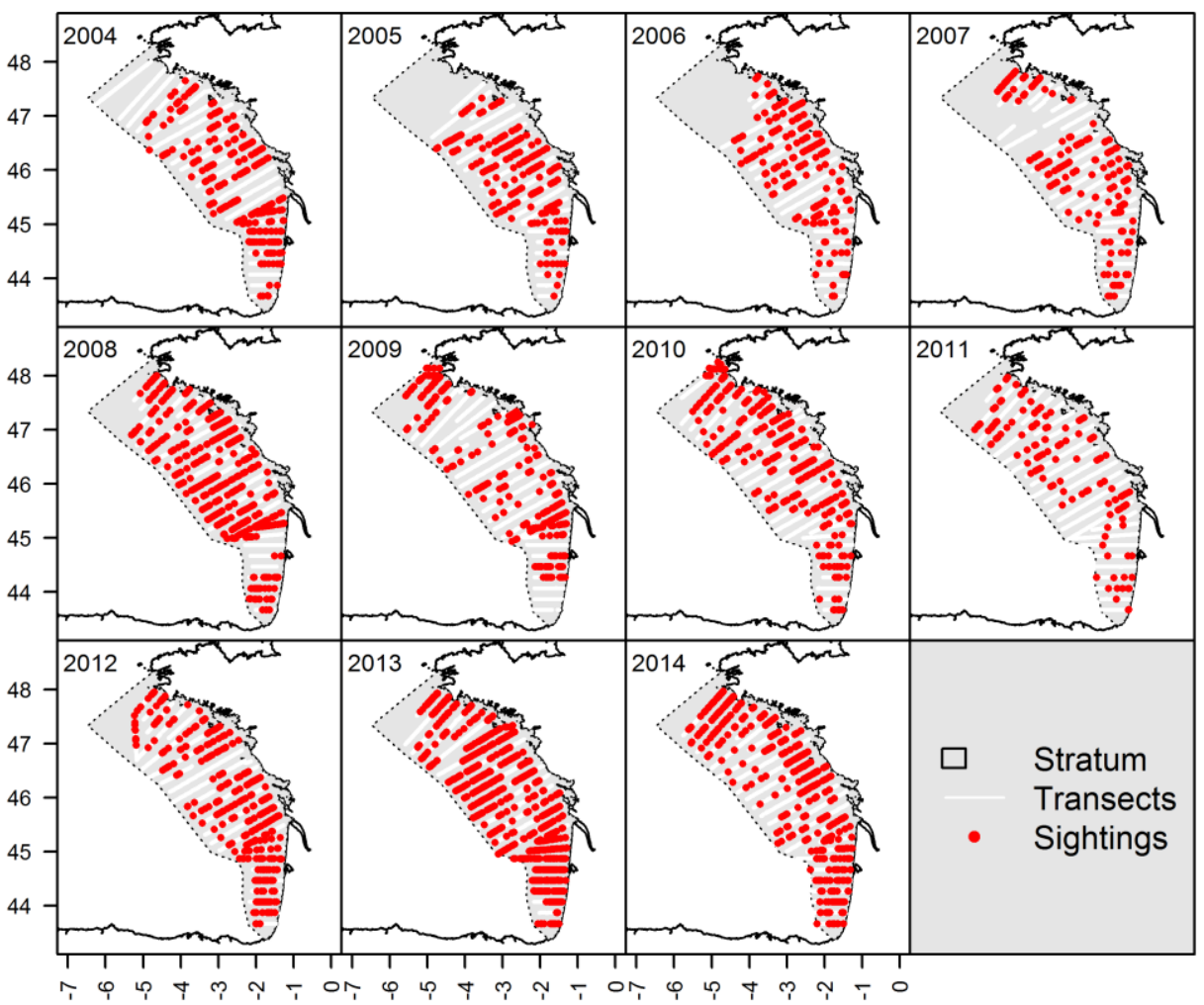

Figure C2 - Distributions of northern gannet sightings associated to acoustic detections from 2004 to 2014. 


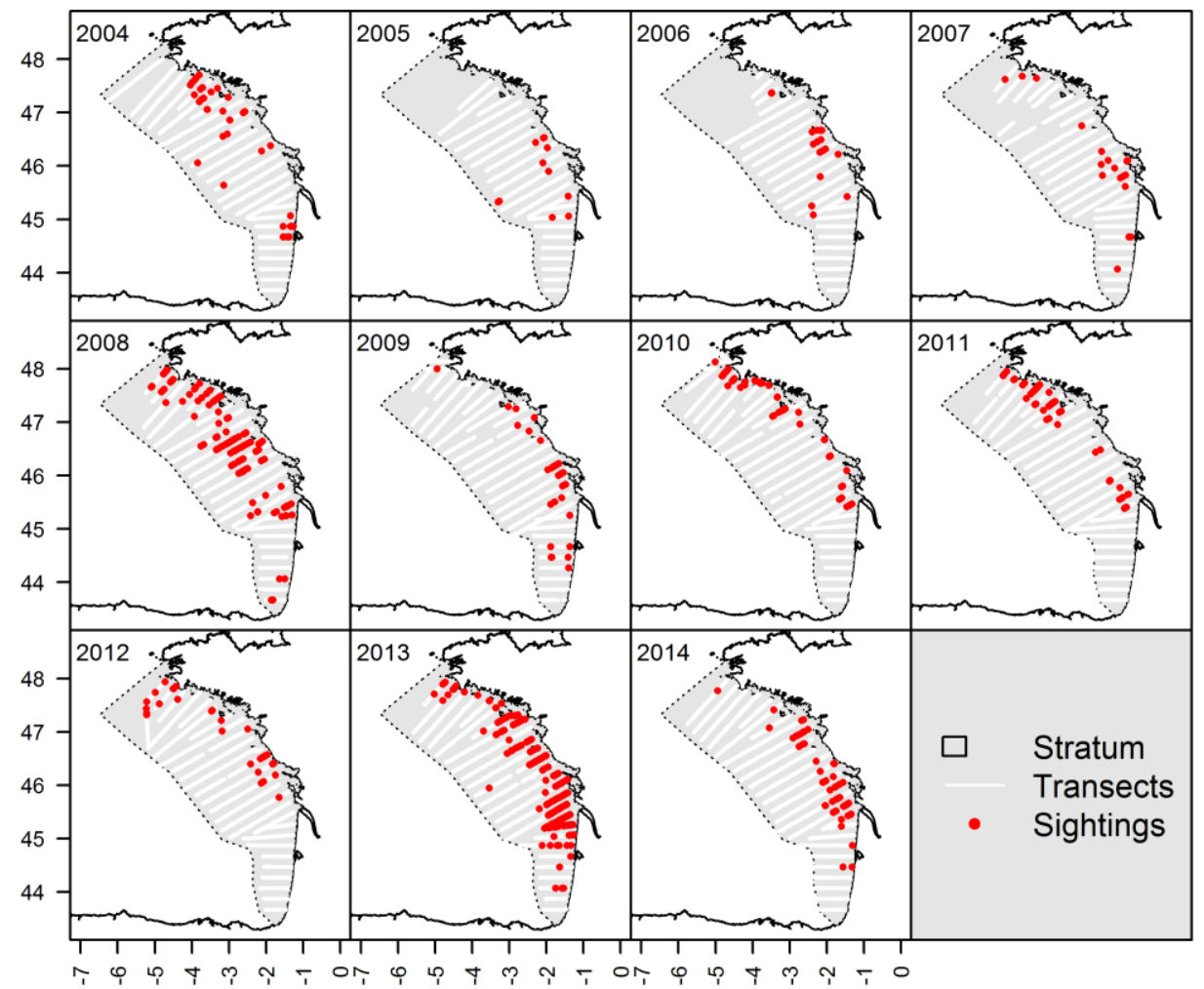

Figure C3 - Distributions of auks sightings associated to acoustic detections from 2004 to 2014.

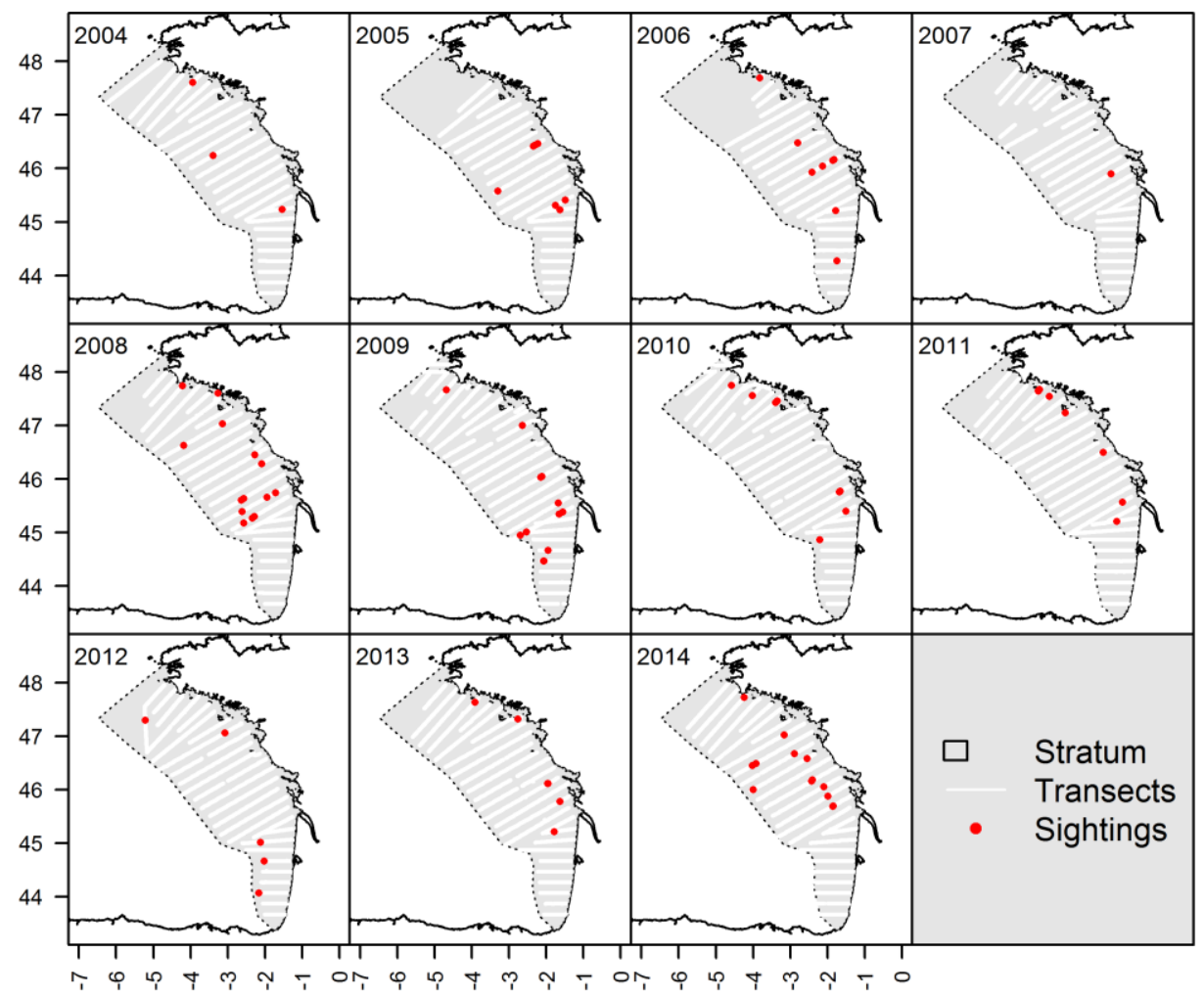

Figure C4 - Distributions of common dolphin sightings associated to acoustic detections from 2004 to 2014. 


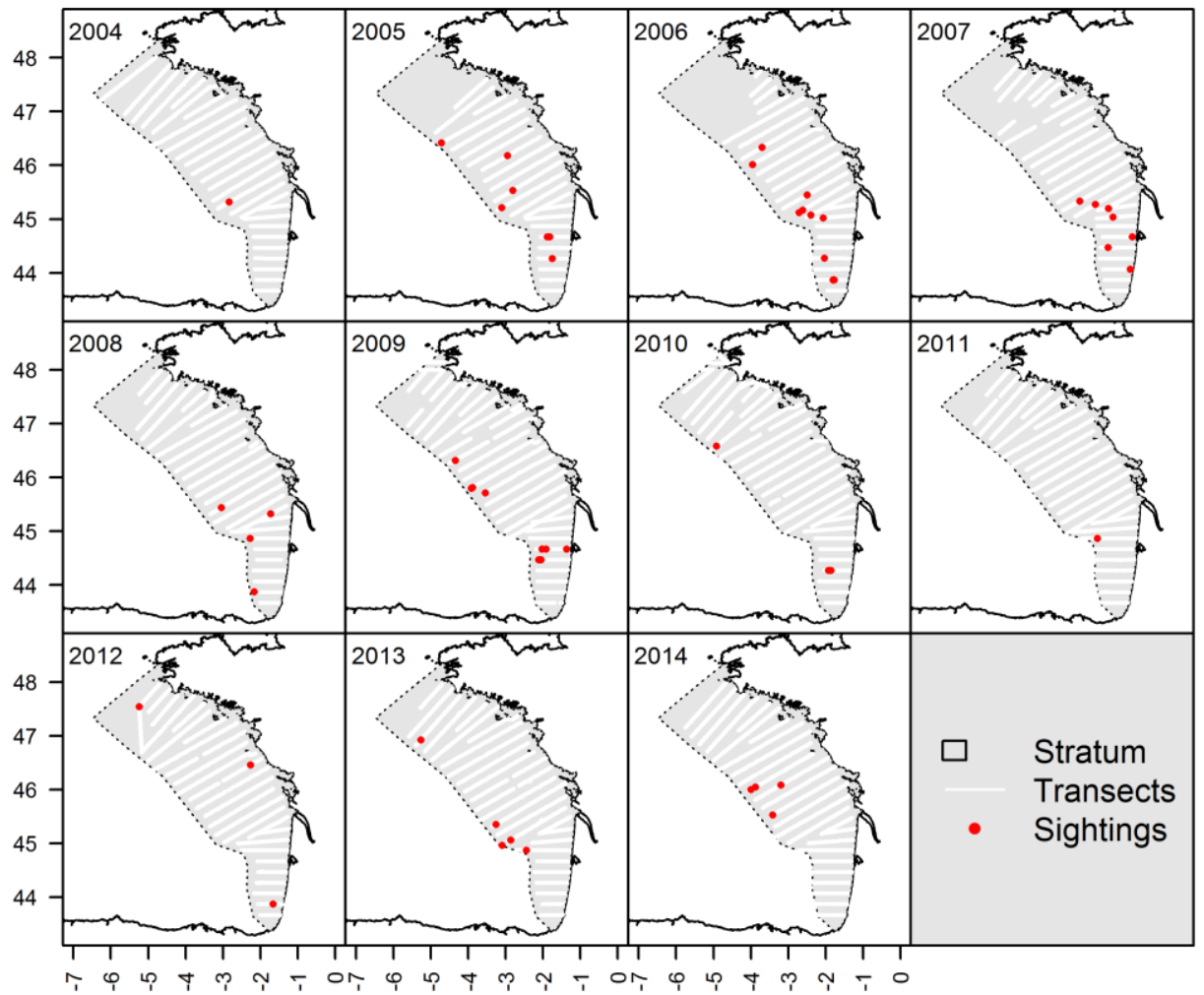

Figure C5 - Distributions of bottlenose dolphin sightings associated to acoustic detections from 2004 to 2014. 